\title{
Traditional medicine in China for ischemic stroke: bioactive components, pharmacology, and mechanisms
}

\author{
Min Xu ${ }^{1}$, Rui-Xia Wu ${ }^{1}$, Xiao-Li Li ${ }^{1}$, Yi-Shen Zeng ${ }^{2}$, Jia-Yang Liang ${ }^{1}, \mathrm{Ke} \mathrm{Fu}^{1}$, Yuan Liang ${ }^{1}$, Zhang Wang $^{2}, *$ \\ ${ }^{1}$ College of Pharmacy, Chengdu University of Traditional Chinese Medicine, 611137 Chengdu, Sichuan, China \\ ${ }^{2}$ College of Ethnomedicine, Chengdu University of Traditional Chinese Medicine, 611137 Chengdu, Sichuan, China \\ *Correspondence: wangzhangcqcd@cdutcm.edu.cn (Zhang Wang)
}

\section{DOI:10.31083/j.jin2101026}

This is an open access article under the CC BY 4.0 license (https://creativecommons.org/licenses/by/4.0/). Submitted: 10 May 2021 Revised: 8 June 2021 Accepted: 11 August 2021 Published: 28 January 2022

Ischemic stroke is an acute cerebrovascular disease and the third most common cause of death after ischemic heart disease. Increasing attention is being paid to finding effective treatments through traditional medicine. Thus, studying the traditional medicine for the treatment of ischemic stroke is of great importance. Traditional medicine in China includes traditional Chinese medicine (TCM) and other ethnic medicines, which is rich in variety and resources. This review first introduces the treatment mechanisms associated with ischemic stroke, such as antioxidant nitrification, antiexcitotoxic, antiapoptotic, anti-inflammatory, antiplatelet and anticoagulation mechanisms. Then, we calculated the frequency of prescription use for ischemic stroke and summarized the treatments for ischemic stroke by investigating 13 drug monographs and standards. We found 192 prescriptions from the traditional medical system for ischemic stroke, including Angong Niuhuang pill, Qishiwei Zhenzhu Pills, Ginkgo biloba leaf, and other traditional Chinese patent medicines and national medicines. There were 398 kinds of traditional medicine, including 301 kinds of plant-based medicines, 54 kinds of animal-based medicines, 28 kinds of mineralbased medicines, and 15 kinds of other medicines. We introduced the names, families, medicinal components, traditional uses, phytochemical information, and pharmacological activities of the commonly used Chinese patent medicines and TCMs. In addition, some chemicals were introduced. These medicines may be potential candidates for the treatment of ischemic stroke. This work provides a reference for the research and clinical use of new drugs for ischemic stroke.

\section{Keywords}

Traditional medicine; Ischemic stroke; Pharmacology; Mechanisms; Traditional Chinese patent medicines; Medicinal materials

\section{Introduction}

Stroke is a kind of acute cerebrovascular disease. Brain tissue damage or dysfunction caused by the sudden rupture or blockage of cerebral vessels prevents blood flow into the brain. Stroke is also the third most common cause of death (4.5\%) after ischemic heart disease (6.1\%) [1]. According to the statistics of the World Health Organization (WHO), 16.9 million people suffer from stroke every year, and the incidence of stroke is 1.5 times higher in males than in females. According to an epidemiological survey, the number of stroke survivors will continue to increase to 77 million by 2030 [2]. Stroke can be divided into hemorrhagic and ischemic types. In traditional Chinese medicine (TCM), hemorrhagic stroke is caused by wind yang harassing the upper body and internal disturbances of the phlegm fire, which results in Qi and blood disorders. In addition, head trauma or brain tumors may also cause hemorrhagic stroke. Ischemic stroke, also known as cerebral infarction, refers to a clinical syndrome caused by the lack of blood supply in the brain and results in local brain ischemia and hypoxic necrosis, along with corresponding neurological deficits. Ischemic stroke is the most common type of stroke and accounts for $60 \%$ to $80 \%$ of cases [3].

Ischemic stroke is a common complication of hypertension, heart disease, and diabetes. Symptoms include limb weakness, sensibility deficits, facial palsy, ataxia, speech problems (aphasia or dysphagia), and visual disturbances [4]. In recent years, the diagnosis of ischemic stroke has depended on computed tomography. Cerebral infarction, local edema, and congestion of surrounding tissue occur after cerebral thrombosis. The diseased area develops swelling and ischemic necrosis and softens after several hours to several days. Historically, the first approved treatment for ischemic stroke in 1996 was thrombolysis by intravenous administration of tissue plasminogen activator [5].

Traditional medicine in China is divided into Chinese material medicine and ethnic medicine. Chinese material medicine includes substances used to prevent, treat, and diagnose diseases and mediate rehabilitation and health care under the guidance of TCM theories. Ethnic medicine refers to medicines that are guided by the theory and practice of the traditional medicine of specific ethnic groups, including Tibetan, Mongolian, and Uygur medicine. At present, the treatment of ischemic stroke involves surgical and drug treatments. In addition to thrombolytic drugs and anticoagulants, Ligusticum chuanxiong, safflower, musk, and other traditional medicines play important roles in the treatment of ischemic stroke by promoting blood circulation, removing stasis, and improving hemodynamics. In addition, traditional the Chi- 


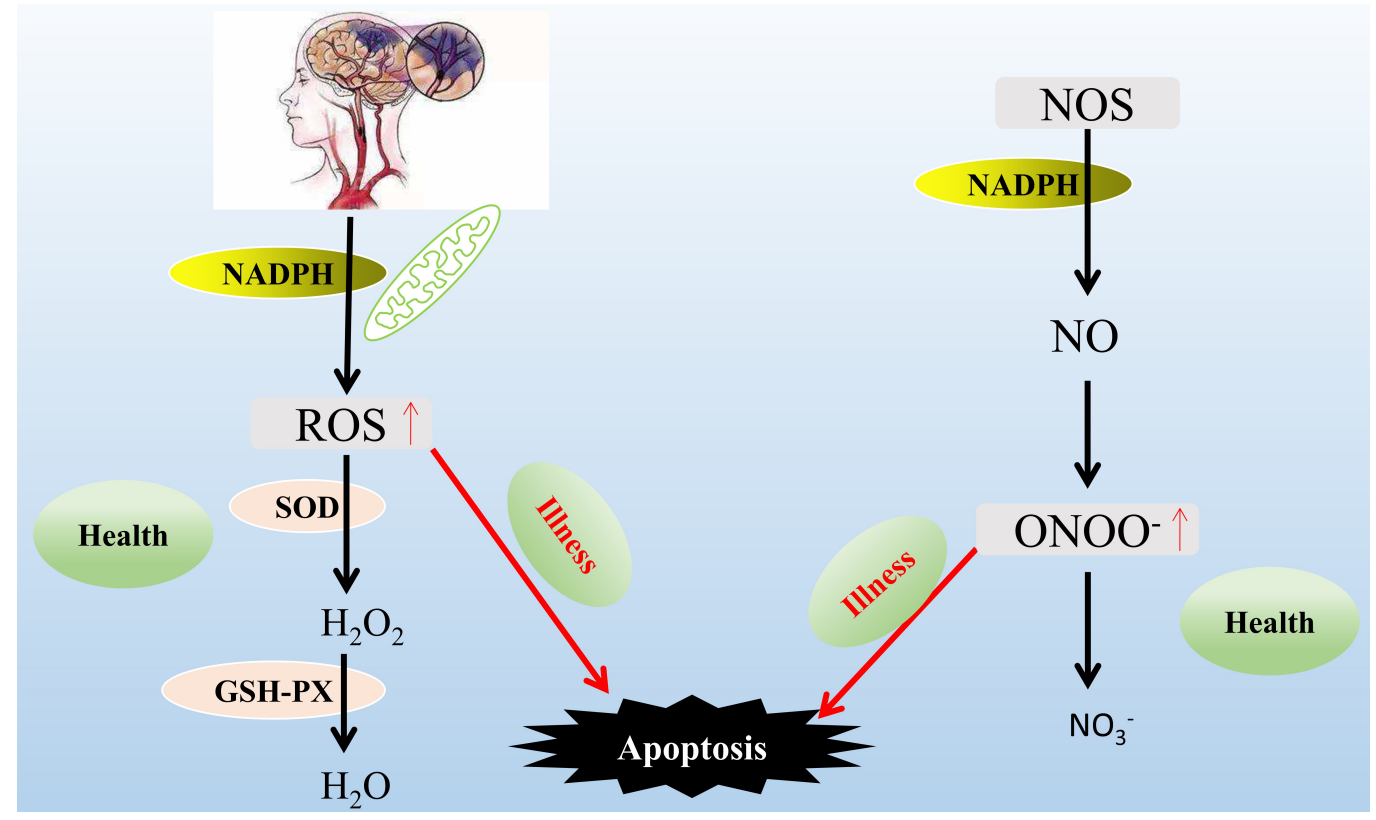

Fig. 1. General pathway of ischemic stroke-induced cell oxidation.

nese patent medicine Angong Niuhuang pill, the Tibetan medicines Qishiwei Zhenzhu Pills and Ershiwuwei Zhenzhu Pills, and the Mongolian medicine treasure pill have good therapeutic effects. Many kinds of traditional medicine can be used for the treatment of ischemic stroke. Chinese material medicine and ethnic medicine can also be classified into plant, animal, and mineral medicines. A summary of these traditional medicines can provide a reference for the development of new traditional medicines for clinical use in the treatment of ischemic stroke.

\section{Pharmacological effects of traditional medicines for ischemic stroke}

Vascular endothelial cell injury leads to atherosclerosis, which leads to cerebral artery occlusion and then ischemic stroke. Neurons in the central ischemic area release and activate the immune response. Astrocytes and microglia are activated and release a series of inflammatory factors, such as tumor necrosis factor- $\alpha$ (TNF- $\alpha$ ), interleukin (IL) $-1 \beta$, and IL-6, which trigger the cellular inflammatory response and cause neuronal death. After ischemia, cells are in an anoxic state. The $\mathrm{Na}^{+}-\mathrm{K}^{+}$pump in neurons in the ischemic penumbra is out of balance, resulting in membrane depolarization, $\mathrm{Ca}^{2+}$ influx, and the release of a large amount of glutamic acid, resulting in excitatory amino acid toxicity. On the one hand, some glutamate binds to the AMPA receptor, further promoting $\mathrm{Ca}^{2+}$ influx, causing DNA damage, mitochondrial dysfunction and other reactions, and inducing apoptosis. On the other hand, some glutamate binds to the $\mathrm{N}$ methyl-D-aspartic acid (NMDA) receptor to release reactive oxygen species (ROS) and reactive nitrogen species (RNS), which lead to oxidative stress. In addition, the expression of autophagy proteins in neurons is upregulated, which leads to autophagy. Furthermore, oxidative stress and other cellular reactions can also induce autophagy. A series of pathological reactions, such as disturbances in energy metabolism, toxic effects of excitatory amino acids, oxidative/nitrative stress injury, inflammatory reactions, apoptosis, and autophagy, occur in ischemic brain tissue [6]. Traditional medicine mainly plays a therapeutic role by exerting antioxidant and nitration, anti-excitotoxic, anti-inflammatory and antiapoptotic effects. In addition, anticoagulation and antiplatelet therapy can also effectively treat ischemic stroke.

\subsection{Antioxidant nitrification}

In ischemic stroke, mitochondria produce a large amount of highly reactive free radicals, such as ROS, through a variety of enzymatic reactions [7]. The excessive accumulation of ROS in the body can cause lipids and proteins to peroxidize and irreversibly damage nucleic acids and sugars, which lead to oxidative stress and apoptosis, ultimately damaging brain tissue [8]. Antioxidants can be divided into endogenous and exogenous antioxidants. Exogenous antioxidants, such as vitamin C, uric acid, bilirubin, albumin, and mercaptan, are hydrophilic and lipophilic [9].

Endogenous antioxidants refer to antioxidants produced by the human body, such as superoxide dismutase (SOD), catalase (CAT), and glutathione peroxidase (GSH-PX). SOD removes ROS generated in the body through a disproportionation reaction. GSH-PX can catalyze the reaction of hydrogen peroxide and reduce glutathione (GSH) to generate water, reduce the level of oxidative stress, and ultimately reduce the production of the lipid peroxidation product malondialdehyde (MDA) to protect cells and tissues from damage [10].

Nitric oxide synthetases, including neuronal NOS, inducible NOS (iNOS), and constitutively expressed endothelial 
NOS, are present in neurons [11]. NOS produces nitric oxide (NO) by reducing nicotinamide adenine dinucleotide phosphate [12]. $\mathrm{NO}$ induces nitrosative stress via $\mathrm{O}^{2-}$ in mitochondria and generates $\mathrm{ONOO}^{-}$, which has strong oxidative properties [13]. The nitration of protein in the brain occurs at a low level under normal conditions; thus, the production of $\mathrm{NO}$ is very low, and most of the $\mathrm{ONOO}^{-}$in the cell is converted to $\mathrm{NO}_{3}{ }^{-}$without attacking other targets [14]. However, during cerebral ischemia, $\mathrm{ONOO}^{-}$exerts its toxic effects through a variety of mechanisms, such as the formation of 3-nitrotyrosine (3-NT) through protein tyrosine nitration [15]. $\mathrm{ONOO}^{-}$overproduction can destroy the blood-brain barrier, break DNA, and disrupt intracellular signal transduction [16]. NO synthesis inhibitors, peroxynitrite scavengers, and decomposition catalysts are used to reduce the production of NO, the activity of $\mathrm{ONOO}^{-}$and the formation of 3NT and exert a neuroprotective effect in cerebral ischemia (Fig. 1).

In recent years, some components of Chinese material medicines have been widely studied as antioxidants that scavenge free radicals. These medicines play an antioxidant role by inhibiting lipid peroxidation, reducing MDA levels, increasing the total antioxidant defense system, and reducing the levels of reactive nitrogen species and ROS. Safranal, a constituent of Crocus sativus (saffron), also has some protective effects on different markers of oxidative damage in the hippocampus of rats. Pretreatment with p-coumaric acid ameliorates brain oxidative stress by reducing MDA while increasing CAT and SOD levels [17].

Nuclear factor erythroid 2-related factor 2 (Nrf2) has increasingly been recognized as a crucial transcription factor that mediates protection against electrophiles and oxidants and enhances cell survival in many tissues. Nrf2 is a key regulator of cellular oxidation at the transcriptional level by controlling the concentration of SOD, CAT, GSH, and heme oxygenase-1 (HO-1). Mangiferin (MF) is a natural glucosyl xanthone found in Chaenomeles sinensis (Thouin) Koehne. The results indicated that MF exerted a certain antioxidant effect and improved the level of oxidative stress induced by ischemia-reperfusion in rat brain tissues. The tetramethylpyrazine analog Z-11 [18] has a protective effect against cerebral ischemia. Nrf2, HO-1, SOD, and GSH levels in ischemic brain tissue were significantly reduced after Z-11 treatment in the context of cerebral ischemia-reperfusion injury (CI/RI). Z-11 may regulate the Nrf2/NOX2 antioxidant defense pathway and play a role in neuroprotection [19].

\subsection{Inhibiting excitotoxicity}

Too many excitatory neurotransmitters, especially glutamate, are released into the synaptic space during ischemia [20]. The accumulation of glutamate results in the overstimulation of glutamate receptors, such as NMDA, alginate, and $\quad \alpha$-amino-3-hydroxy-5-methyl-4-isoxazolepropionic acid, on neurons, and $\mathrm{Na}^{+}, \mathrm{Cl}^{-}$, and $\mathrm{Ca}^{2+}$ flow through channels controlled by these receptors $[21,22]$. These events to the development of cytotoxic edema, and the increase in intracellular calcium leads to an increase in oxidative stress, which mediates cell damage. Intracellular calcium also activates various enzymes, such as lipases, proteases, and endonucleases, which may damage DNA, cellular proteins, and lipids and lead to cell death [23].

Some traditional medicine ingredients can reduce glutamate release, inhibit glutamate receptor stimulation, and reduce cellular calcium overload. Cactus extract and astragaloside have neuroprotective effects against NMDA- and KAinduced neurotoxicity [24].

\subsection{Inhibiting apoptosis}

Apoptosis is initiated by external signals or through internal mitochondrial signaling. Apoptosis is characterized by distinctive morphological changes in the nucleus and cytoplasm, such as chromatin cleavage at regularly spaced sites and the endonucleolytic cleavage of genomic DNA [25].

Apoptosis induced by cerebral ischemia generally occurs through two pathways (Fig. 2). (a) The mitochondriamediated apoptotic pathway plays a key role in neuronal apoptosis after ischemic stroke [26]. The increase in the intracellular calcium activator bid (tBid); the interaction between tBid and apoptosis proteins, such as Bad and Bax, on the mitochondrial membrane [7]; the increase in mitochondrial membrane permeability and the decrease in membrane potential; the release of cytochrome $\mathrm{c}$ and apoptotic protein-activating factor-1; and the activation of procaspase9, caspase-9, and caspase-3 lead to apoptosis. (b) In the extrinsic cascade, extracellular Fas ligand binds to Fas death receptors and activates caspase-8 [17].

Some components of traditional medicine can inhibit the internal or external apoptotic pathway. For example, astragaloside IV, which is isolated from Astragalus propinquus Schischkin [27], can promote the binding of hexokinase and mitochondria to protect neurons from apoptosis and DNA damage. Astragaloside IV can inhibit various cell death pathways of neurons injured by hypoxia and glucose deficiency, reduce damage to mitochondrial function, and protect neurons. The water-soluble component of Salvia miltiorrhiza, magnesium lithospermate B (MLB), inhibits the activation of caspase-3 after $\mathrm{CI} / \mathrm{RI}$, and up-regulates p-Akt in the ischemic hemisphere, thereby protecting CI/RI [28].

\subsection{Inhibiting inflammation}

Inflammation is a series of complex interactions between inflammatory cells and molecules with neurotoxic or neuroprotective effects [29]. Cerebral ischemia can lead to a substantial increase in the levels of proinflammatory cytokines, such as TNF- $\alpha$, IL- $1 \beta$, and IL-6, and chemokines, such as IL-8, macrophage inflammatory protein- $1 \alpha$, and monocyte chemotactic protein-1 (MCP-1) [30]. On the one hand, proinflammatory cytokines, which are regulated by proteins and the caspase family of inflammatory factors, directly or indirectly lead to neuronal death, such as apoptosis and necrosis [31]. On the other hand, proinflammatory cytokines overactivate microglia to transform these cells into phagocytes, 


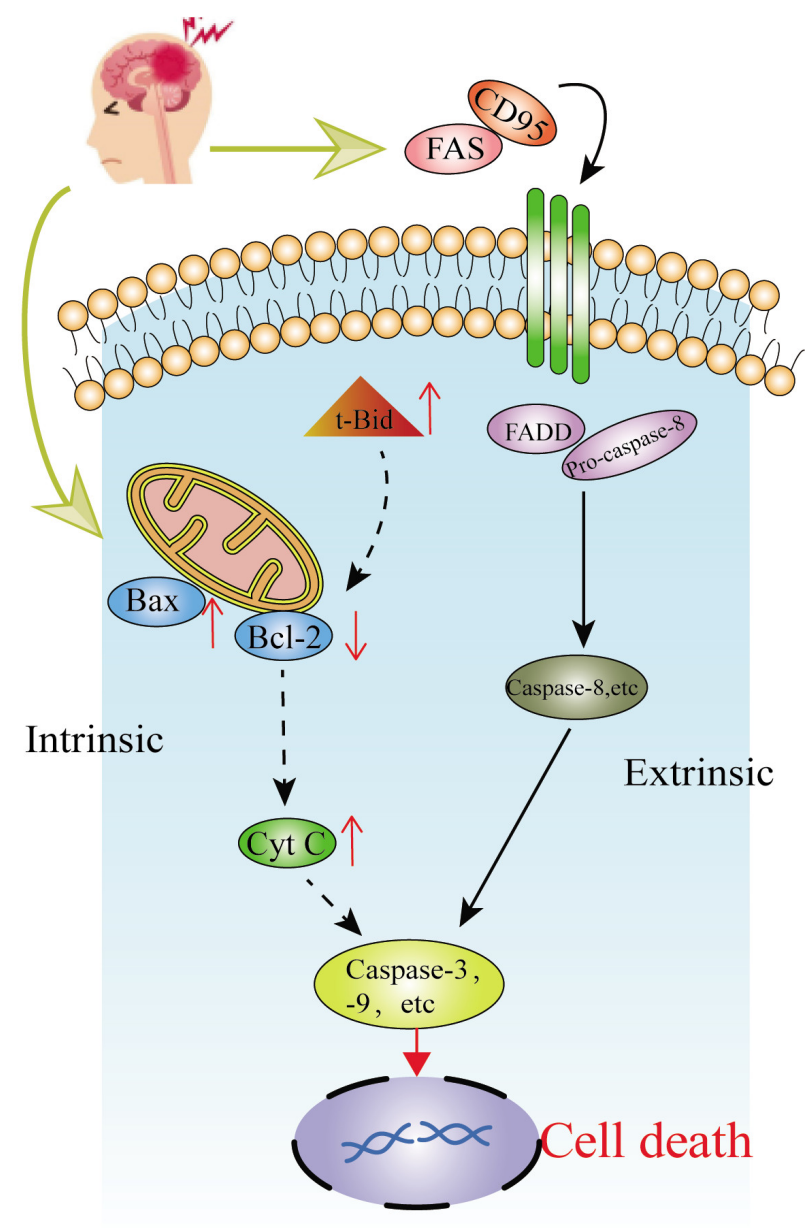

Fig. 2. The general way of ischemic stroke-induced apoptosis.

which release many kinds of toxic substances that participate in the inflammatory reaction, increase the permeability of the blood-brain barrier, further exacerbate brain edema, and ultimately cause tissue necrosis [32, 33].

The bioactive components of many traditional medicines have remarkable anti-inflammatory effects. Xanthanol, the active component of Cnidium monnieri (L.) Cusson., has neuroprotective effect on CI/RI after cerebral ischemia by inhibiting the production of proinflammatory mediators such as IL- $1 \beta$, TNF- $\alpha$, IL-8, iNOS, and NO. In addition, Ilex pubescens Hook. et Arn., Pinellia ternata (Thunb.) Breit., and Gastrodia elata Bl. exert neuroprotective effects against cerebral ischemia through anti-inflammatory and other mechanisms.

\subsection{Inhibiting platelets and coagulation}

Cerebral thrombosis is the most common cause of cerebral ischemia, and platelets play an important role in the process of thrombosis. When the vascular endothelium is damaged, specific receptors on the surface of vascular endothelial cells, such as glycoprotein, P-selectin and integrin, bind to subendothelial proteins such as hemophilia-related factor, fibronectin, vitronectin and thrombospondin, facilitating platelet adherence to damaged endothelial cells. After the adherent platelets are stimulated, they cause small platelet actin rearrangement, platelet pseudopodia formation, cell body extension, $\alpha$ - and $\delta$-granular membrane fusion with the small platelet membrane and the release of components such as TG, PF, fibrinogen, ADP, and 5-HT through intracellular $\mathrm{Ca}^{2+}$ signal transduction, inducing the aggregation of blood platelets [34]. After ischemic stroke, the activation of platelets can exacerbate microcirculation disturbances and ischemic brain tissue damage via neurotoxic substances or platelet aggregation. Thrombosis of the common carotid artery in rats can cause transient platelet aggregation, which can significantly expand the cerebral infarction area caused by global cerebral ischemia [35].

Thrombin is the final product of the blood coagulation cascade. Thrombin acts on fibrinogen in the circulation and produces fibrin, which leads to thrombosis. Thrombin can induce platelet aggregation, induce the expression of $\mathrm{P}$ selectin in endothelial cells, and increase the permeability of endothelial cells. Thrombin combined with fibrin can prevent the inactivation of plasma anticoagulant factor and heparin and prolong the action time of these factors [36].

At present, most antiplatelet and anticoagulant drugs are Western medicines, such as aspirin, clopidogrel and prasugrel. Some Chinese herbal medicines also have antiplatelet and anticoagulant effects. Xu used an arteriovenous shunt thrombosis model and an adenosine 5'-diphosphate (ADP)induced acute pulmonary embolism model to observe the antithrombotic effect of supercritical $\mathrm{CO}_{2}$ extract from Salvia miltiorrhiza (SCED). It was found that the activated part of ADP inhibited the phosphorylation of PLC $\beta 3$ and PKC in sced pretreated platelets. SCED can reduce cerebral ischemia injury, which may be mediated by its antiplatelet activation [37]. Osthole can significantly inhibit thrombosis in rats, reduce the death or hemiplegia of mice induced by collagen adrenaline thrombosis, and inhibit platelet aggregation induced by various factors. Osthole can inhibit thrombosis through antiplatelet and anticoagulant effects, thus protecting against cerebral ischemia [38].

\subsection{Activating autophagy}

Autophagy is a degradation process by which cells maintain cell homeostasis by lysosomal-mediated degradation of biomacromolecules, damaged organelles or pathogenic microorganisms in the cytoplasm. Under physiological conditions, autophagy is very low in cells. In the nervous system, moderate autophagy is considered to have neuroprotective effects [39]. During autophagy, the components to be degraded in the cytoplasm are isolated in double-membrane vesicles to form autophagosomes, and then the autophagosome and lysosome fuse to produce a single-membrane autophagic lysosome, which is degraded by lysosomal hydrolase [40]. LC3 and beclin-1 are two marker proteins of autophagy, and LC3 is present in the form of cytoplasmic LC3 (LC3-I) and membrane LC3 (LC3-II). The ratio of LC3-I and LC3-II can reflect the level of autophagy. The Bcl-2/beclin-1 complex is considered to be a molecular switch that regulates the 
formation of autophagic membranes [41]. However, when autophagy is overactivated, autophagy can not only mediate cytoprotection but also degrade the nucleus and cause cell death [42].

Many components of traditional medicines can achieve neuroprotective effects by activating moderate levels of autophagy, such as Schisandrin A and Oxymatrine. The rats were given Schisandrin A through lateral ventricle after 90 minutes of ischemia [43]. The results showed that Schisandrin A upregulated the autophagy proteins beclin-1 and LC3II, and immunofluorescence double-labeling showed that autophagic activity was mainly present in neurons. These results suggest that the neuroprotective effect of schisandrin $\mathrm{A}$ is related to the enhancement of autophagy in the ischemic penumbra. Oxymatrine was injected intraperitoneally 60 minutes before cerebral ischemia [44], measured cell apoptosis by the TUNEL method, the expression of P53, Bax, dissociated Caspase-3, LC3 and P62, and evaluated autophagy. It was found that oxymatrine treatment reduced tissue damage in I/R rats, inhibited cell apoptosis, and promoted autophagy.

\subsection{Other pharmacological effects}

In recent years, the concept of the neurovascular unit (NVU) has been proposed, which has changed the goal of cerebral protection after ischemia from protection at the level of individual neurons in the past to the structural protection of nerve cells and blood vessels. The neurovascular unit is composed of microvessels, astrocytes, neurons and their axons, microglia, oligodendrocytes and other supporting cells. Traditional Chinese medicine-mediated protection of the neurovascular unit of ischemic stroke mainly manifests as neuroprotection, vascular protection and glial protection. The neuroprotective mechanisms include antioxidation, inhibiting neuronal apoptosis, inflammation, and excitatory neurotoxicity [45].

The blood-brain barrier (BBB) is the core structure of the neurovascular unit. The $\mathrm{BBB}$ can prevent a variety of substances from entering the brain but allow nutrients and metabolites to pass and maintain the relative stability of the internal environment of the nervous system [46]. During cerebral ischemia, the blood-brain barrier is destroyed, and the permeability is increased, which then causes edema and hemorrhage, further exacerbating the ischemic condition. Ligustrazine may restore tight junction function by upregulating claudin-5 expression and reducing BBB permeability after cerebral ischemia-reperfusion in rats, thus reducing brain edema after ischemia-reperfusion [47]. Tanshinone can also upregulate the expression of claudin in the bloodbrain barrier. Citrulline, paeoniflorin and other components in Gualou Guizhi granule can enter brain tissue through the $\mathrm{BBB}$ and have neuroprotective effects on rats with cerebral ischemia-reperfusion injury [48].

Glial cells can secrete a variety of cytokines and neurotrophic factors, which play important roles in maintaining the survival of neurons. Under physiological conditions, the increase in the number of glial cells plays a beneficial role in supporting active neurons, which is beneficial to the learning and memory function of the brain [49]. When cerebral ischemia occurs, glial cells undergo excessive proliferation, and proliferative glial cells produce and release neurotoxic substances such as tumor necrosis factor and NO and promote the development of injury. It has been reported that Scutellaria barbata flavonoids can inhibit $\beta 25$-35-induced damage to rat cortical astrocytes. The water extract of Huanglian Jiedu decoction can protect neurons in the ischemic penumbra by inhibiting the excessive activation of astrocytes and modulating the expression of connexin [50].

\section{Summary and statistical analysis of traditional medicines for ischemic stroke}

We manually searched 13 drug monographs and standards (Table 1), including "new Chinese patent medicine", "Pharmacopoeia of the People's Republic of China (Part 1 of the 2015 edition)", "Ministry-promulgated Standards", "Tibetan Medicine Standards", and "Ethnic Medicine Prescriptions", to identify the functions and indications of prescriptions in the context of "cardiovascular and cerebrovascular embolism, cerebral infarction, cerebral thrombosis, ischemic stroke, stroke, paralysis, hemiplegia, constriction, skewed mouth and eyes, unclear speech, white pulse disease, and black and white pulse disease". We collected the indications for these prescriptions and the names, original species, families, and medicinal parts of the traditional medicines in these prescriptions. The active components and mechanisms of these traditional medicines in the treatment of ischemic stroke were collected from databases (i.e., Wanfang, Weipu, CNKI, ISI Web of Science, and Science Direct). The botanical names of the original plants were obtained from references and verified through the "Flora of China (http://www.iplant .cn/frps)" database based on their Chinese names.

We identified 398 kinds of traditional medicines (Supplementary Table 1) among the 192 prescriptions we collected. The traditional medicines were distributed among 132 families. The most common families were Leguminosae (4.5\%), Umbelliferae (3.5\%), Compositae (3.5\%), Labiatae (3.5\%), Rutaceae (3.2\%), Zingiberaceae (3\%), Ranunculaceae (2.5\%), Liliaceae (2.5\%), Rosaceae (2.0\%), and Araceae (2.0\%), as shown in Fig. 3. Among these traditional medicines, botanical medicinal materials accounted for $75.6 \%$, animal medicine accounted for $13.6 \%$, mineral medicine accounted for $7.0 \%$, and other traditional medicines accounted for $3.7 \%$. Botanical medicinal materials were the main source of these traditional medicines. Root (20.5\%), stem (14.7\%), fruit (12.4\%), whole grass $(8.4 \%)$, and seed $(8.1 \%)$ were the most commonly used plant parts (Fig. 4). 
Table 1. The related information of the 13 monographs referenced in our paper.

\begin{tabular}{|c|c|c|c|c|c|}
\hline No. & Monograph & Author & Publication date of the monograph & The type of the monograph & $\begin{array}{c}\text { The number of prescriptions for ischemic } \\
\text { stroke extracted from the monograph in our } \\
\text { paper }\end{array}$ \\
\hline 1 & $\begin{array}{l}\text { Newly compiled Chinese medicine } \\
\text { application guide }\end{array}$ & Yang, S. S. & 1993 & Print edition & 113 \\
\hline 2 & $\begin{array}{l}\text { Pharmacopoeia of the People's Re- } \\
\text { public of China }\end{array}$ & Health Bureau & 2015 & Print edition & 69 \\
\hline 3 & $\begin{array}{l}\text { Drug standards issued by the Min- } \\
\text { istry }\end{array}$ & Health Bureau & 2015 & Print edition & 18 \\
\hline 4 & Tibetan Medicine Standards & $\begin{array}{l}\text { Health Bureau of Tibet, Qinghai, Sichuan, Gansu, Yun- } \\
\text { nan, and Xinjiang }\end{array}$ & 1979 & Print edition & 7 \\
\hline 5 & Waitai Miyao & Wang, $\mathrm{T}$. & 618-907 AD & Print edition & 6 \\
\hline 6 & Dai medicine prescription & Jia, K. L., Zhao, Y. H. & 2007 & Print edition & 5 \\
\hline 7 & Xianshou Lishang Xuduan Mifang & Lan, D. R. & 618-907 AD & Print edition & 3 \\
\hline 8 & $\begin{array}{l}\text { Shaolin Temple Secret Recipe Col- } \\
\text { lection }\end{array}$ & Teaching by De,C. written by De,Q. & 1986 & Print edition & 3 \\
\hline 9 & Emei Shenxiao Yanfang & Wang, F. Q. & 1992 & Print edition & 3 \\
\hline 10 & $\begin{array}{l}\text { Prescription preparation of ethnic } \\
\text { medicine }\end{array}$ & Song, M. X. & 2014 & Print edition & 2 \\
\hline 11 & Zhulingsi Nvke Quanshu & Bamboo forest monk & 1636-1912 AD & Print edition & 1 \\
\hline 12 & Dianxue Mijue & Xue, D. & 1938 & Print edition & 1 \\
\hline 13 & Jingshi Zhenlei Beiji Bencao & Tang, S. W. & $960-1127 \mathrm{AD}$ & Print edition & 1 \\
\hline
\end{tabular}




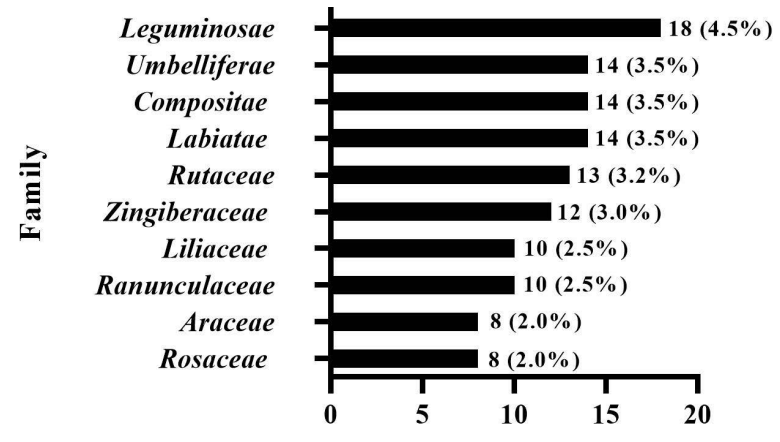

Number of traditional medicines

Fig. 3. Family distribution of traditional medicines for ischemic stroke.

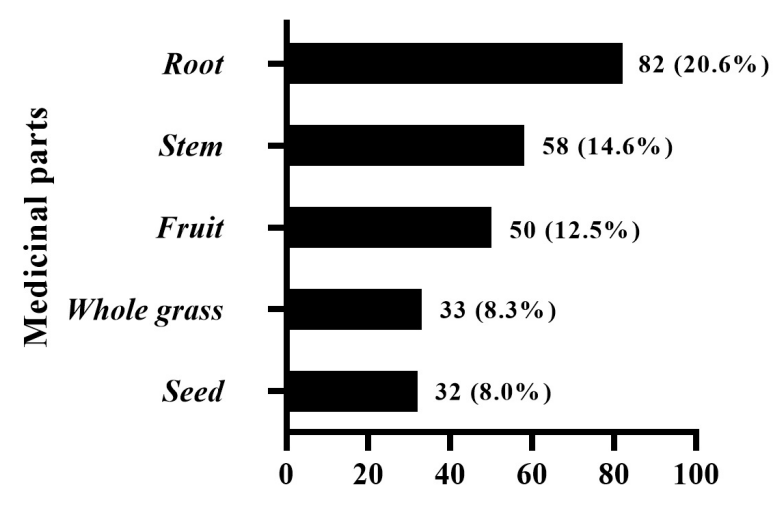

Number of traditional medicines

Fig. 4. Parts of traditional medicines used in the treatment of ischemic stroke.

\section{Traditional Chinese patent medicines for ischemic stroke}

Traditional Chinese patent medicines are Chinese material medical products made of raw Chinese material medical components processed into a specific form according to the prescription and preparation process under the guidance of TCM theory. Traditional Chinese patent medicine is convenient to transport, easy to consume, and stable in efficacy and thus has occupied a very important position in the pharmaceutical industry. Many of the 192 prescriptions we studied have been made into very common Chinese patent medicines. We selected five of these as a detailed introduction (Fig. 5).

\subsection{Angong Niuhuang pill}

Angong Niuhuang pill is the most famous emergency TCM. This pill originated from the plague debates by $\mathrm{Wu}$ Jutong, a plague expert in the Qing Dynasty. The pre- scription consists of 11 kinds of Chinese materia medicines [51]: bezoar (Bos taurus domesticus Gmelin), Curcuma aromatica Salisb., Rhinoceros unicornis L., musk (Moschus), pearl (Pernulo), Gardenia jasminoides Ellis, Coptis chinensis Franch, Scutellaria baicalensis Georgi, cinnabar, realgar, and borneol. The rhinoceros horn in the modern formula of Angong Niuhuang pill is replaced with a buffalo horn, and the natural bezoar is replaced with an artificial bezoar. This medicine clears away heat, detoxifies, alleviates convulsions, and opens up the mind [52]. This pill has been used as a key drug for treating febrile convulsions, stroke and coma [53].

Yang [54] reported that Angong Niuhuang Pill could significantly reduce the level of NO and the activity of NOS in brain tissue. Liu [55] reported that Angong Niuhuang pill could improve blood and plasma viscosity and substantially increase the platelet aggregation rate and erythrocyte aggregation index. In addition, $\mathrm{Fu}$ [56] and $\mathrm{Yu}$ [57] used Angong Niuhuang Pill in the treatment of stroke, and the total effective rates were $86 \%$ and $100 \%$ respectively.

The realgar and cinnabar in Angong Niuhuang pill contain $90 \% \mathrm{As}_{2} \mathrm{~S}_{3}$ and $96 \% \mathrm{HgS}$ [58], respectively. As and $\mathrm{Hg}$ are heavy metals that have potential nephrotoxic effects. Lei [59] systematically evaluated the safety, adverse drug reactions, and adverse events of using Angong Niuhuang pill in the existing literature and found that the incidence of toxicity was low. Most of the adverse reactions and adverse events were attributed to the improper use of Angong Niuhuang pill, such as overuse or use with incompatible medicines.

\subsection{Qishiwei Zhenzhu Pills}

Qishiwei Zhenzhu Pills [60], one of the most representative and precious medicines, is composed of Pernulo, Santalum album L., Dalbergia odorifera T. Chen, C. sativus L., B. taurus domesticus Gmelin, Moschus, and more than 70 flavor components. This medicine is now included in the Pharmacopoeia of the People's Republic of China (2015 edition). This preparation harmonizes qi and blood, awakens the brain, and opens the mind. This medicine is used for the treatment of "black and white pulse disease", "dragon blood disorder", stroke, paralysis, hemiplegia, epilepsy, cerebral hemorrhage, concussion, heart disease, hypertension, and neurological disorders [61].

Qishiwei Zhenzhu Pills [62] is rich in essential trace elements, especially zinc, cobalt, copper, manganese, and vanadium, which are closely related to the treatment of cardiovascular diseases. Modern pharmacological studies [63] have shown that Qishiwei Zhenzhu Pills can counteract the convulsions induced by thiosemicarbazide and improve the learning and memory deficits induced by ethanol and the memory acquisition induced by anisodine in mice. This treatment can also increase the cerebral blood flow of rabbits by clearing dampness. Qishiwei Zhenzhu Pills induces sedation, inhibits convulsion, improves memory, microcirculation and cerebral blood circulation, inhibits thrombosis, and reduces blood pressure. An [64] used Qishiwei Zhenzhu Pills to treat 50 patients with paralysis and 16 patients with epilepsy. The 


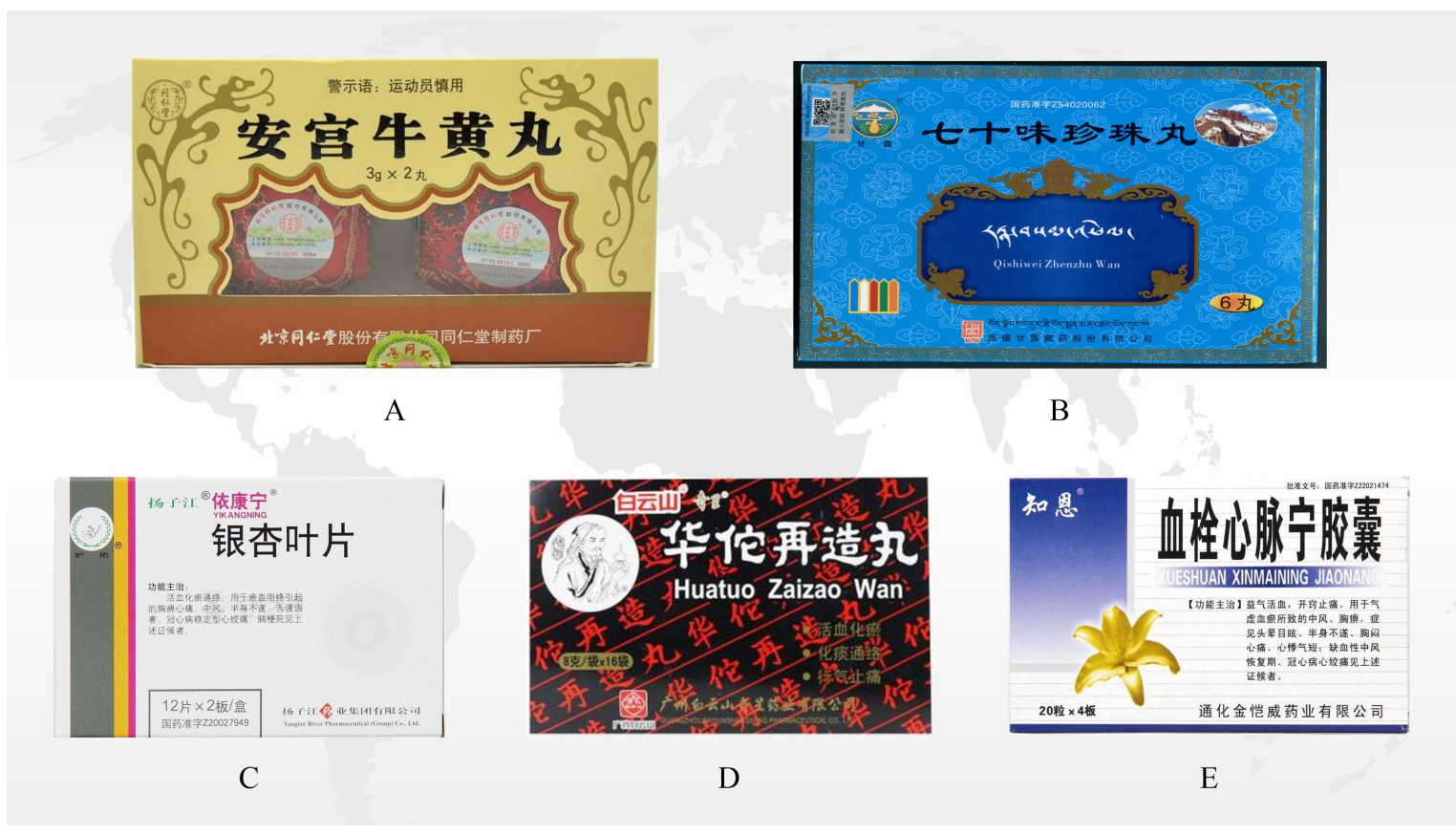

Fig. 5. Common Chinese traditional patent medicines for ischemic stroke. (A) Angong Niuhuang Pill. (B) Qishiwei Zhenzhu Pills. (C) Ginkgo biloba leaf. (D) Huatuo Zaizao Pill. (E) Xueshuan Xinmai Ning.

total effective rate was 100\%; the effective rate was $91 \%$ for 22 patients with hypertension and 79\% for 14 patients with concussion. Wu [65] used Qishiwei Zhenzhu Pills to treat ischemic cerebral obstruction. This treatment can alleviate the behavioral disorders caused by ischemic cerebral obstruction, reduce platelet aggregation and adhesion, reduce infarct size, and improve the efficacy of treatment for cerebral arteriosclerosis.

\subsection{Ginkgo biloba leaf}

Ginkgo biloba leaf [66] is made into a film-coated tablet by boiling and extraction. Ginkgo biloba leaf contains total flavonoids and terpene lactones, activates blood circulation, removes blood stasis, and dredges collaterals. This medicine can be used for chest pain, heart pain, stroke, hemiplegia, stiff tongue, sluggish speech, stable angina pectoris, and cerebral infarction caused by blood stasis. The standard extract of Ginkgo biloba leaves [67] has been clinically used in Europe to treat the symptoms of brain dysfunction in patients with primary degenerative dementia syndrome. A large number of in vivo and in vitro studies have supported this clinical application.

Wang [68] reported that Ginkgo biloba extract can significantly prolong the survival time of mice with acute cerebral ischemia induced by bilateral common carotid artery ligation, and reduce the damage of hippocampal subcellular structure after reperfusion. Yuan [69] reported that Ginkgo biloba leaves can improve the learning and memory function of vascular dementia rats caused by multiple cerebral infarction, significantly increase the activity of SOD in hippocampus, inhibit the activity of ache, and significantly reduce the level of MDA. Clinically, there were significant differences in blood viscosity, plasma viscosity, hematocrit, erythrocyte sedimentation rate and blood flow velocity of middle cerebral artery before and after treatment in 180 patients with ischemic cerebrovascular disease treated with Ginkgo biloba $(P<0.01)$ [70]. The results showed that Ginkgo biloba has a good therapeutic effect on ischemic brain injury.

\subsection{Huatuo Zaizao pill}

Huatuo Zaizao pill is composed of L. chuanxiong Hort, Evodia rutaecarpa (Juss.) Benth., borneol, and other medicines. This treatment has been used for more than 200 years in clinical practice and is included in the Chinese Pharmacopoeia. This treatment activates blood circulation, removes blood stasis, resolves phlegm, dredges collaterals, activates qi and alleviates pain. The Huatuo Zaizao pill is often used to treat stroke paralysis, constriction, numbness, deviation of the mouth and eyes, and unclear speech [71, 72].

Strychnos nux-vomica L., borneol, Schisandra chinensis, Radix ginseng rubra, and other active ingredients in the pill contain volatile oils [73], which can excite the central nervous system, increase the oxygen supply in the brain, improve the working ability of the cortex, and promote the functional recovery of brain cells. Liu [74] reported that Huatuo Zaizao pill can inhibit thrombosis in vitro, prolong thrombosis time in vivo, reduce blood viscosity, inhibit platelet aggregation, and improve cerebral blood supply, oxygen supply and pia mater. Huatuo Zaizao pill activates blood circulation, removes blood stasis, and antagonizes thrombosis, as observed by changes in microcirculation. Hence, this treatment is an ideal drug for treating the sequelae of cerebral thrombosis [75]. 


\subsection{Xueshuan Xinmai Ning}

Xueshuan Xinmai Ning [76] is composed of Ligusticum chuanxiong Hort., Salvia miltiorrhiza Bge., Whitmania pigra Whitman, and other medicines. This medicine has the function of aromatic resuscitation, activates blood circulation, and removes blood stasis. Clinically, this medicine can be used to treat many cardiovascular and cerebrovascular diseases because it can improve the blood supply of the cardiovascular and cerebrovascular systems by expanding blood vessels and protecting endothelial cells. Modern pharmacological studies have shown that the protection of vascular endothelial cells may be achieved through modulating the expression of genes related to multiple signal transduction pathways in vascular endothelial cells [77].

Han [78] used high-performance liquid chromatography and ultraperformance liquid chromatography coupled with electrospray ionization and tandem quadrupole timeof-flight mass spectrometry to preliminarily identify $63 \mathrm{com}$ ponents in Xueshuan Xinmai Ning capsules, namely, 20 saponins, 4 flavonoids, 15 phenolic acids, 8 sterols, 4 bile acids, 10 hydroquinones, and 2 other compounds. Wang [79] divided 66 patients with transient cerebral ischemia into three groups according to the transcranial Doppler method: an anterior cerebral circulation group, a posterior cerebral circulation group, and a mixed circulation group. Xueshuan Xinmai Ning capsules were taken orally, and the different systemic insufficiencies in blood supply were compared with those of the 20 cases in the oral nimodipine group. The results showed that the Xueshuan Xinmai Ning group had the most improvement in dizziness caused by insufficient blood supply in the three groups, and Xueshuan Xinmai Ning was better than nimodipine in improving tinnitus. Yang [80] reported that Xueshuan Xinmaining can significantly reduce the infarct size of rats with acute myocardial infarction within 24 hours and 7 days after. Thus, Xueshuan Xinmai Ning capsules have a protective effect on acute myocardial ischemia.

\section{Traditional medicines for ischemic stroke}

The data of the traditional medicines in the prescriptions were gathered to determine the frequency of use of each medicine in the prescription and understand the most commonly used medicines for the treatment of ischemic stroke. As a result, 192 prescriptions for the treatment of ischemic stroke were collected from the drug monographs and standards. The medicines with a frequency of use that was higher than $1 \%$ are shown in Table 2 (Ref. [28, 81-100]). The top five were Chuanxiong Rhizoma (frequency: 70 times), safflower (60 times), Angelica sinensis and musk (53 times each), and Salvia miltiorrhiza (49 times). The following sections provide a detailed review of the names, original plant types, traditional uses, active ingredients, and biopharmacological activities of these five medicines (Figs. 6,7).

\subsection{Chuanxiong Rhizoma}

Chuanxiong Rhizoma (known as Chuanxiong in Chinese) is the dried rhizome of Umbelliferae L. chuanxiong Hort. This rhizome is produced in Dujiangyan, Pengzhou, Chongzhou, and other places in Sichuan Province [97]. In TCM theory, Chuanxiong Rhizoma is warm in property and pungent in flavor and activates qi, promotes blood circulation, expels wind, and alleviates pain [101]. Chuanxiong Rhizoma is clinically used in prescriptions for the treatment of migraine, myocardial ischemia, and cerebral ischemia. Its antiinflammatory, antiapoptotic, antioxidative stress activities, activate autophagy, and its neuroprotection effects are related to the treatment of cerebral ischemia [102]. At present, more than 170 compounds in Chuanxiong Rhizoma have been isolated and identified. These compounds include phthalic acid, terpenoids and enols, polysaccharides, alkaloids, organic acids, and esters [97]. Ferulic acid and ligustrazine are the main bioactive and pharmacodynamic components and are also used as indicators of the quality of Chuanxiong Rhizoma in drug standards.

The extract of Chuanxiong Rhizoma has been proven to have some pharmacological activities related to cerebral ischemia. For example, ferulic acid has a neuroprotective effect on rats with transient middle cerebral artery occlusion (MCAO) [103]. The mechanism is related to the expression of superoxide radicals, intercellular adhesion molecule- 1 , and $\mathrm{NF}-\kappa \mathrm{B}$ in rats with transient MCAO. Lin [104] reported that Ligustrazine can significantly increase the expression level of microtubule associated protein-2 in the infarcted area after stroke and improve neurological function. Kao reported that Ligustrazine significantly improved the apoptosis and neuron loss induced by cerebral ischemia-reperfusion, inhibited the activation of microglia and the recruitment of inflammatory cells and MCP-1 after cerebral ischemia in rats. Studies have shown that Ligustrazine is completely absorbed in the body and widely distributed, mainly concentrated in tissues and organs with rich blood flow. It can also quickly pass through the blood-brain barrier and persist in the brain. The liver may be the main metabolic site of Ligustrazine, the drug and its metabolites are mainly excreted by the kidney, and the content of protodrug in urine is very low [105].

\subsection{Safflower}

Safflower is the dried flower of Carthamus tinctorius L. In China, safflower is widely cultivated in various locations in Henan, Sichuan, Xinjiang, and Zhejiang provinces. The safflower is warm in property and pungent in flavor; promotes blood circulation, relieves stasis, and relieves pain; and is used to treat coronary heart disease, stroke, gynecological diseases, angina pectoris, and hypertension [106].

More than 200 compounds have been isolated from safflower, including flavonoids, phenylethanoid glycosides, coumarins, fatty acids, steroids, and polysaccharides [98]. Among these compounds, hydroxysafflor yellow A, kaempferol-3-o-rutinoside (KRS) and kaempferol3-o-glucoside (KGS) are related to cerebral ischemia. Hydroxysafflor yellow A and kaempferide are often used as quality control markers in the pharmaceutical industry and drug standards. The level of hydroxysafflor yellow A 


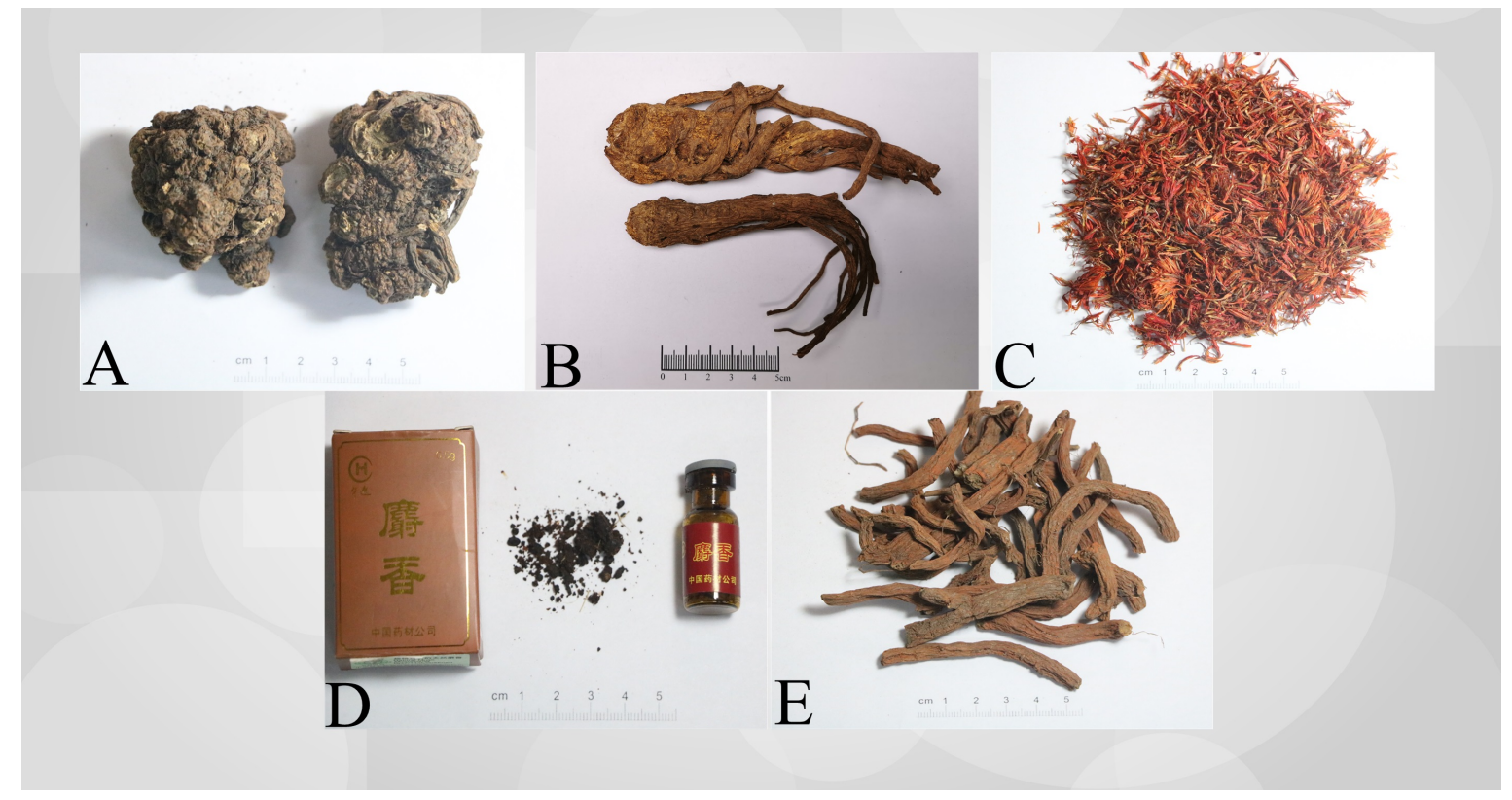

Fig. 6. Common traditional medicines for ischemic stroke. (A) Chuanxiong Rhizoma. (B) Angelica sinensis. (C) Safflower. (D) Musk. (E) Salvia miltiorrhiza.<smiles>COc1cc(/C=C/C(=O)O)ccc1O</smiles>

Ferulic acid (MF: $\mathrm{C}_{10} \mathrm{H}_{10} \mathrm{O}_{4}$ Compound CID: 445858)

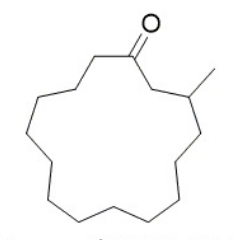

Muscone (MF: $\mathrm{C}_{16} \mathrm{H}_{30} \mathrm{O}$ Compound CID: 10947)

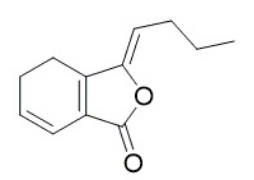

Ligustilide (MF: $\mathrm{C}_{12} \mathrm{H}_{14} \mathrm{O}_{2}$ Compound CID: 5319022) $\mathrm{OH}$<smiles>Cc1nc(C)c(C)nc1C</smiles>

Ligustrazine (MF: $\mathrm{C}_{8} \mathrm{H}_{12} \mathrm{~N}_{2}$ Compound CID: 14296)<smiles>O=C(/C=C/c1ccc(O)cc1)C1=C(O)C(O)([C@H]2O[C@H](CO)[C@@H](O)[C@H](O)[C@H]2O)C(O)=C([C@H]2O[C@H](CO)[C@@H](O)[C@H](O)[C@H]2O)C1=O</smiles>

Hydroxysafflower yellow A (MF: $\mathrm{C}_{27} \mathrm{H}_{32} \mathrm{O}_{18}$ Compound CID: 102200539)<smiles>Cc1ccc2oc3c(c2c1)C(=O)C(=O)c1c(C)cccc1-3</smiles>

Tanshinone I I B (MF: $\mathrm{C}_{19} \mathrm{H}_{18} \mathrm{O}_{4}$ Compound CID: 318797 )<smiles>C[C@H]1O[C@H](OC[C@H]2O[C@H](Oc3c(-c4ccc(O)cc4)oc4cc(O)cc(O)c4c3=O)[C@@H](O)[C@H](O)[C@H]2O)[C@H](O)C[C@H]1O</smiles>

Kaempferol-3-o-glucoside (MF:

$\mathrm{C}_{21} \mathrm{H}_{20} \mathrm{O}_{11}$ Compound CID: 5282102)<smiles>O=c1c(OC2O[C@H](CO)[C@@H](O)[C@H](O)[C@H]2O)c(-c2ccc(O)cc2)oc2cc(O)cc(O)c12</smiles>

Kaempferol-3-o-rutinoside (MF: $\mathrm{C}_{27} \mathrm{H}_{30} \mathrm{O}_{15}$ Compound CID: 5318767)<smiles>Cc1coc2c1C(=O)C(=O)c1c-2ccc2c1CCCC2(C)C</smiles>

Tanshinone I (MF: $\mathrm{C}_{18} \mathrm{H}_{12} \mathrm{O}_{3}$ Compound CID: 114917)<smiles>O=C(/C=C\c1cccc2c1C(C(=O)OC(Cc1ccc(O)c(O)c1)C(=O)O)C(c1ccc(O)c(O)c1)O2)OC(Cc1ccc(O)c(O)c1)C(=O)O</smiles>

Salvianolic acid B (MF: $\mathrm{C}_{36} \mathrm{H}_{30} \mathrm{O}_{16}$ Compound CID: 11629084)

Fig. 7. The structure of the main compounds of common medicinal materials. The chemical structures of compounds were derived from PubChem (https://pubchem.ncbi.nlm.nih.gov/). 
Table 2. Traditional medicines for the treatment of ischemic stroke.

\begin{tabular}{|c|c|c|c|c|c|c|c|c|c|c|c|}
\hline \multicolumn{2}{|c|}{ No. Chinese name } & Latin name & Family & Life form & Used part & $\begin{array}{l}\text { Reported stroke } \\
\text { related bioactivity }\end{array}$ & Dose & $\begin{array}{l}\text { Pharmacological effects re- } \\
\text { lated to stroke }\end{array}$ & $\begin{array}{l}\text { Mechanism of action related to } \\
\text { stroke }\end{array}$ & Used frequency & Reference \\
\hline 1 & Chuan-xiong & $\begin{array}{l}\text { Ligusticum chuanxiong } \\
\text { Hort. }\end{array}$ & Umbelliferae & Herb & Rhizome & $\begin{array}{l}\text { Ferulic acid, ligus- } \\
\text { trazine }\end{array}$ & $100 \mathrm{mg} / \mathrm{kg}$; i.g. & $\begin{array}{l}\text { Antioxidant, Inhibiting in- } \\
\text { flammation and Inhibiting } \\
\text { apoptosis }\end{array}$ & $\begin{array}{l}\text { Inhibition of superoxide radi- } \\
\text { cals, ICAM-1 and NF- } \mathrm{xB} \text { ex- } \\
\text { pression and production of mi- } \\
\text { croglia, inflammatory cells and } \\
\text { MCP-1 }\end{array}$ & $70(2.77 \%)$ & [97] \\
\hline 2 & Hong-hua & Carthamus tinctorius $\mathrm{L}$. & Compositae & Herb & Flower & $\begin{array}{l}\text { Hydroxysafflower } \\
\text { yellow a, Kaempferol- } \\
\text { 3-O-rutinoside, } \\
\text { kaempferol-3-O- } \\
\text { glucoside }\end{array}$ & $0.4 \mathrm{~g} / \mathrm{kg}$; i.g. & $\begin{array}{l}\text { Anti-nitrification, Inhibit- } \\
\text { ing inflammation and In- } \\
\text { hibiting apoptosis }\end{array}$ & $\begin{array}{l}\text { Reduced nitrotyrosine, in- } \\
\text { hibited STAT3 and NF-xB, } \\
\text { JAK2/STAT3 pathways }\end{array}$ & $60(2.38 \%)$ & [98] \\
\hline 3 & Dang-gui & $\begin{array}{l}\text { Angelica sinensis (Oliv.) } \\
\text { Diels. }\end{array}$ & Umbelliferae & Herb & Root & Angelica essential oil & $0.25,0.5,1 \mathrm{~g} / \mathrm{kg}$; i.g. & Inhibiting apoptosis & $\begin{array}{l}\text { Decrease the expression of } \\
\text { 4-hydroxy-2-nonenal, cytc and } \\
\text { lyse Caspase-3, and inhibit the } \\
\text { apoptosis of hippocampal CA1 } \\
\text { cells }\end{array}$ & $53(2.1 \%)$ & [81] \\
\hline 4 & She-xiang & $\begin{array}{l}\text { Moschus berezovskii } \\
\text { Flerov., Moschus sifanicus } \\
\text { Przewalski., Moschus } \\
\text { moschiferus Linnaaeus. }\end{array}$ & Moschus & Animal & Secretion & Muscone & $0.9 \mu \mathrm{m}$; i.g. & Inhibiting apoptosis & $\begin{array}{l}\text { The protective effect of Mus- } \\
\text { cone on cerebral ischemia } \\
\text { depends on the activation of } \\
\text { PI3K/Akt signaling pathway }\end{array}$ & $53(2.1 \%)$ & [99] \\
\hline 5 & Dan-shen & Salvia miltiorrhiza Bunge & Labiatae & Herb & $\begin{array}{l}\text { Root and rhi- } \\
\text { zome }\end{array}$ & $\begin{array}{l}\text { Salvianolic acid, Tan- } \\
\text { shinone }\end{array}$ & 10 mg/kg, i.p. & $\begin{array}{l}\text { Inhibiting inflammation } \\
\text { and Inhibiting apoptosis }\end{array}$ & $\begin{array}{l}\text { Increase or maintain endoge- } \\
\text { nous inflammatory cytokines } \\
\text { (IL-4 and IL-13) to protect neu- } \\
\text { ron death caused by ischemia in } \\
\text { CA1 }\end{array}$ & 49 (1.94\%) & [100] \\
\hline 6 & Shao-yao & Paeonia lactiflora Pall. & Ranunculaceae & e Herb & Root & Paeoniflorin & $10,15,20 \mathrm{mg} / \mathrm{kg}$; i.v. & $\begin{array}{l}\text { Inhibiting inflammation } \\
\text { and Inhibiting apoptosis }\end{array}$ & $\begin{array}{l}\text { Reduce the levels of ED1, IL- } \\
1 \beta \text { TNF- } \alpha \text { and ICAM-1 in mi- } \\
\text { crovascular, inhibit the cell and } \\
\text { apoptosis of MPO immunoreac- } \\
\text { tivity }\end{array}$ & $47(1.86 \%)$ & [82] \\
\hline 7 & Mu-xiang & Aucklandia lappa Decne & Compositae & Herb & Root & Costunolide & $2.7 \%$; i.g. & Inhibiting apoptosis & $\begin{array}{l}\text { Regulate mitochondrial cyto-c } \\
\text { pathway and increase the ex- } \\
\text { pression of Bcl-2 protein }\end{array}$ & $46(1.82 \%)$ & [83] \\
\hline
\end{tabular}


Table 2. Continued.

\begin{tabular}{|c|c|c|c|c|c|c|c|c|c|c|c|}
\hline No. & Chinese name & Latin name & Family & Life form & Used part & $\begin{array}{l}\text { Reported stroke } \\
\text { related bioactivity }\end{array}$ & Dose & $\begin{array}{l}\text { Pharmacological effects re- } \\
\text { lated to stroke }\end{array}$ & $\begin{array}{l}\text { Mechanism of action related to } \\
\text { stroke }\end{array}$ & Used frequency & Reference \\
\hline 8 & Huang-qi & $\begin{array}{l}\text { Astragalus membranaceus } \\
\text { (Fisch.) Bge }\end{array}$ & Labiatae & Herb & Root & Astragaloside A & $12.5,25,50 \mathrm{mg} / \mathrm{kg}$; i.g. & Inhibiting apoptosis & $\begin{array}{l}\text { It inhibited the mRNA expres- } \\
\text { sion of Fas, FasL, Caspase- } 8 \text { and } \\
\text { Bax/Bcl- } 2 \text { and the protein lev- } \\
\text { els of caspase- } 8 \text {, Bid, cleaved } \\
\text { caspase- } 3 \text { and Cyto C. }\end{array}$ & $43(1.7 \%)$ & [28] \\
\hline 9 & Bing-pian & $\begin{array}{l}\text { Cinnamomum camphora } \\
\text { (L.) Presl }\end{array}$ & Lauraceae & Compound & Synthetics & L-borneol, R-borneol & $0.2,0.6 \mathrm{~g} / \mathrm{kg}$; i.g. & $\begin{array}{l}\text { Inhibiting apoptosis and } \\
\text { Inhibiting inflammation }\end{array}$ & $\begin{array}{l}\text { Increase serum VEGF level, de- } \\
\text { crease serum TNF- } \alpha \text { level and } \\
\text { Bax/Bcl-2 ratio }\end{array}$ & $42(1.66 \%)$ & [84] \\
\hline 10 & Gan-cao & $\begin{array}{l}\text { Glycyrrhiza uralensis } \\
\text { Fisch. }\end{array}$ & Leguminosae & Herb & $\begin{array}{l}\text { Root and rhi- } \\
\text { zome }\end{array}$ & Liquiritigenin & $10,20,40 \mathrm{mg} / \mathrm{kg}$, i.g. & $\begin{array}{l}\text { Antioxidant and Inhibiting } \\
\text { apoptosis }\end{array}$ & $\begin{array}{l}\text { Increase GSH/GSSG ratio and } \\
\text { SOD, CAT, GSH PX activity, } \\
\text { decrease } 8-O H d G \text { and TUNEL } \\
\text { positive cells. }\end{array}$ & $41(1.63 \%)$ & [85] \\
\hline 11 & Di-long & $\begin{array}{l}\text { Pheretimaraspergillum } \\
\text { (E.Perrier)., Pheretima } \\
\text { vulgaris Chen., Pheretima } \\
\text { guillelmi (Michaelsen)., } \\
\text { Pheretimar pectinifera } \\
\text { Michaelsen }\end{array}$ & Megascolecidae & aeAnimal & $\begin{array}{l}\text { Whole body } \\
\text { without the } \\
\text { viscera }\end{array}$ & Pheretima aspergillum & $0.25,0.5,1.0 \mathrm{~g} / \mathrm{kg}$, oral & Inhibiting apoptosis & $\begin{array}{l}\text { Decrease neuron death, GFAP } \\
\text { proliferation and S100B protein } \\
\text { expression }\end{array}$ & $39(1.55 \%)$ & [86] \\
\hline 12 & Niu-huang & $\begin{array}{l}\text { Bos taurus domesticus } \\
\text { Gmelin }\end{array}$ & Bovidae & Animal & $\begin{array}{l}\text { Bile-cyst,bile } \\
\text { duct or the } \\
\text { stones in the } \\
\text { liver tube }\end{array}$ & $\begin{array}{l}\text { Taurine, Ursodeoxy- } \\
\text { cholic Acid, tau- } \\
\text { roursodeoxycholic } \\
\text { acid }\end{array}$ & $20 \mathrm{~g} / \mathrm{kg}$, i.p. & $\begin{array}{l}\text { Antioxidant and Inhibiting } \\
\text { apoptosis }\end{array}$ & $\begin{array}{l}\text { Inhibit excitatory amino acid } \\
\text { neurotoxicity and endoplasmic } \\
\text { reticulum stress }\end{array}$ & $36(1.43 \%)$ & [87] \\
\hline 13 & San-qi & $\begin{array}{l}\text { Panax notoginseng (Burk.) } \\
\text { F.H Chen }\end{array}$ & Araliaceae & Herb & Root & $\begin{array}{l}\text { Panax notoginseng } \\
\text { polysaccharide }\end{array}$ & $100,300 \mathrm{mg} / \mathrm{kg}$, i.g. & $\begin{array}{l}\text { Antioxidant and Inhibiting } \\
\text { inflammation }\end{array}$ & $\begin{array}{l}\text { Increase the activity of GSH Px, } \\
\text { SOD and the content of IL-10, } \\
\text { decrease the content of MDA, } \\
\text { TNF- } \alpha \text { and IL- } 1 \beta \text {, improve the } \\
\text { antioxidant capacity of brain tis- } \\
\text { sue and inhibit inflammatory } \\
\text { factors }\end{array}$ & $36(1.43 \%)$ & [88] \\
\hline 14 & Niu-xi & $\begin{array}{l}\text { Adhyranthes } \\
\text { Blume }\end{array}$ & Amaranthaceael & aeHerb & Root & $\begin{array}{l}\text { Achyranthes bidentata } \\
\text { polypeptide }\end{array}$ & $0.1,0.2,1.0 \mathrm{mg} / \mathrm{kg}$, i.v. & Inhibiting apoptosis & $\begin{array}{l}\text { Regulate the expression of } \\
\text { apoptosis related genes, restore } \\
\text { mitochondrial membrane po- } \\
\text { tential, regulate mitochondrial } \\
\text { dysfunction, reduce the release } \\
\text { of mitochondrial apoptosis fac- } \\
\text { tors, and inhibit the production } \\
\text { of ROS in cells }\end{array}$ & $33(1.31 \%)$ & [89] \\
\hline
\end{tabular}


Table 2. Continued.

\begin{tabular}{|c|c|c|c|c|c|c|c|c|c|c|c|}
\hline No. & Chinese name & Latin name & Family & Life form & Used part & $\begin{array}{l}\text { Reported stroke } \\
\text { related bioactivity }\end{array}$ & Dose & $\begin{array}{l}\text { Pharmacological effects re- } \\
\text { lated to stroke }\end{array}$ & $\begin{array}{l}\text { Mechanism of action related to } \\
\text { stroke }\end{array}$ & Used frequency & Reference \\
\hline 15 & Ge-gen & $\begin{array}{l}\text { Pueraria lobata (Willd.) } \\
\text { Ohwi }\end{array}$ & Leguminosae & Vine & Root & Pueraria flavonoids & $50,100,200 \mathrm{mg} / \mathrm{kg}$, i.g. & Antioxidant & $\begin{array}{l}\text { Improve the activity of SOD, re- } \\
\text { duce the content of MDA and } \\
\text { resist the damage of oxygen free } \\
\text { radical }\end{array}$ & $31(1.23 \%)$ & [90] \\
\hline 16 & Chen-xiang & $\begin{array}{l}\text { Aquilaria sinensis (Lour.) } \\
\text { Gilg }\end{array}$ & Thymelaeacea & eTree & $\begin{array}{l}\text { Wood con- } \\
\text { tains resin }\end{array}$ & Water extraction & - & Antioxidant & $\begin{array}{l}\text { Improve energy metabolism and } \\
\text { reduce energy and oxygen con- } \\
\text { sumption }\end{array}$ & $30(1.19 \%)$ & [91] \\
\hline 17 & Tian-ma & Gastrodia elata Bl. & Orchidaceae & Herb & Rhizome & Gastrodin & $15,30,60 \mathrm{mg} / \mathrm{kg}$, i.g. & Inhibiting apoptosis & $\begin{array}{l}\text { Down regulating the expression } \\
\text { of caspase-3 mRNA and reduc- } \\
\text { ing the apoptosis of brain neu- } \\
\text { rons }\end{array}$ & $28(1.11 \%)$ & [92] \\
\hline 18 & Tao-ren & $\begin{array}{l}\text { Prunus persica (L.) Batsch., } \\
\text { Prunus davidiana (Carr.) } \\
\text { Franch }\end{array}$ & Rosaceae & Tree & Seed & Peach kernel decoction & $2,4 \mathrm{~g} / \mathrm{kg}$, i.g. & $\begin{array}{l}\text { Inhibiting apoptosis, An- } \\
\text { tioxidant }\end{array}$ & $\begin{array}{l}\text { Increase the activity of neurons } \\
\text { and decrease the water content } \\
\text { of brain tissue }\end{array}$ & $27(1.07 \%)$ & [93] \\
\hline 19 & Di-huang & $\begin{array}{l}\text { Rehmannia glutinosa Li- } \\
\text { bosch. }\end{array}$ & $\begin{array}{l}\text { Scrophula- } \\
\text { riaceae }\end{array}$ & Herb & $\begin{array}{l}\text { Tuberous } \\
\text { root }\end{array}$ & $\begin{array}{l}\text { Rehmannia polysac- } \\
\text { charide }\end{array}$ & $5,10,20 \mathrm{mg} / \mathrm{kg}$, i.p. & Antioxidant & $\begin{array}{l}\text { Enhance the activity of SOD, } \\
\mathrm{Na}^{+}-\mathrm{K}^{+} \text {-ATPase and } \mathrm{Ca}^{2+} \\
\mathrm{Mg}^{2+} \text {-ATPase in mitochondria } \\
\text { of ischemic area }\end{array}$ & $27(1.07 \%)$ & [94] \\
\hline 20 & Ding-xiang & $\begin{array}{l}\text { Eugenia caryophyllata } \\
\text { Thunb. }\end{array}$ & Myrtaceae & Tree & Bud & Eugenol & 200 mg/kg, i.p. & $\begin{array}{l}\text { Inhibiting inflamma- } \\
\text { tion,Inhibiting apoptosis }\end{array}$ & $\begin{array}{l}\text { By up regulating the expres- } \\
\text { sion of BDNF protein in brain, } \\
\text { we can regulate the function of } \\
\text { brain area and improve the in- } \\
\text { jury after ischemia }\end{array}$ & $27(1.07 \%)$ & [95] \\
\hline 21 & Shui-zhi & $\begin{array}{l}\text { Whitmania pigra Whit- } \\
\text { man., Hirudo nipponica } \\
\text { Whitman., Whitmania } \\
\text { acranulata Whitman. }\end{array}$ & Hirudinidae & Animal & Whole body & Hirudo polypeptide & $20,40,80 \mathrm{mg} / \mathrm{kg}$, i.p. & Antioxidant & $\begin{array}{l}\text { Increase SOD activity, decrease } \\
\text { MDA content, inhibit lipid per- } \\
\text { oxidation and increase antioxi- } \\
\text { dant enzyme activity. }\end{array}$ & $26(1.03 \%)$ & [96] \\
\hline
\end{tabular}


is required to be greater than $1.0 \%$, and the kaempferide content should be greater than $0.05 \%$ [107].

Some active components and extracts of safflower have pharmacological effects on cerebral ischemia. The water extract of safflower can improve brain injury in rats with CI/RI by antioxidation and anti-inflammatory mechanisms. Sun and Yang [108] reported that hydroxysafflor yellow a can reduce the formation of nitrotyrosine, inhibit iNOS mediated no production, clear peroxynitrite, and down regulate NMDA receptor containing NR2B to protect neurons from death. Yu [109] reported that KRS or KGS can improve the shape and structure of cortical neurons, reduce the number of apoptotic cells, down regulate the expression of p-JAK2, p-STAT3, caspase-3, and Bax, reduce the immune activity of Bax, and increase the protein expression and immune response of Bcl-2 [110].

Safflower is also used in combination with other drugs to clinically treat cerebral ischemic diseases. For example, the combination of $A$. propinquus Schischkin and safflower can ameliorate cerebral infarction with qi deficiency and blood stasis syndrome. $\mathrm{Xu}$ [111] reported that the combination of salvianolic acid A in Salvia miltiorrhiza Bge. and hydroxysafflor yellow A in safflower has a synergistic effect on CI/RI in rats.

\subsection{Angelica sinensis}

Angelica sinensis (Oliv.) Diels is an important Chinese material medicine. Its use in China can be traced back to "Shennong Bencao Jing” nearly 2000 years ago [112]. Angelica sinensis is one of the most commonly used Chinese material medicines for tonification, hematopoiesis, tumor inhibition, and inflammation inhibition [113]. This medicine is used to treat menstrual disorders, amenorrhea and dysmenorrhea. Currently, more than 70 formulas containing Angelica sinensis are recorded in the Chinese Pharmacopoeia [114]. Angelica sinensis naturally grows in cool, high-altitude mountainous regions between $2500 \mathrm{~m}$ and $3000 \mathrm{~m}$ in Gansu, Hubei, Shaanxi, Sichuan, and Yunnan provinces [115]. Among them, Gansu is the main production area of Angelica sinensis and accounts for $90 \%$ of the total output. Min County has the largest yield among the cultivation areas in Gansu and produces more than 6000 tons, which makes up $70 \%$ of the nationwide production and $80 \%$ of the exported materials. Angelica sinensis that is cultivated in Gansu is thought to be the best quality and is regarded as an authentic and superior medicinal material (Daodi yaocai) [116]. Angelica sinensis can be divided into three distinct parts, namely, the head, body, and tail. The three parts have different therapeutic effects. The head is used to stop bleeding, the body is used to nourish the blood, and the tail is used to quicken the blood. The effect of Angelica sinensis on the nervous system is related to pain relief [117]. Angelica sinensis has many chemical components, and ferulic acid and volatile oils are its main bioactive and pharmacodynamic components and quality control index.

Angelica sinensis essential oil (AO), a major pharmacologically active component of Angelica sinensis (Oliv.) Diels, pos- sesses hemogenesis activities, analgesic activities, and sedative effects and is used to treat a range of conditions, including menstrual disturbances and anemia. Over 40 compounds have been identified in $\mathrm{AO}$, with the major constituent being ligustilide (LIG) [118].

It has been reported that $\mathrm{AO}$ can promote the production of IL-10 by inhibiting the secretion of pro-inflammatory cytokines (TNF- $\alpha$, IL-1 $\beta$, and IL-6), inflammatory mediators (5-HT, PGE2, and NO) and inflammatory related enzymes (iNOS and COX-2). Lig can reduce the number of apoptotic cells; down regulate the pro apoptotic protein $\mathrm{p} 53$ and cleaved caspase-3. Lig attenuates ischemic brain injury through anti apoptotic pathway [119].

\subsection{Musk}

Musk is the dried secretion of the musk pod of the adult male deer. The medical use of musk was first recorded in "Shennong Bencao Jing" (approximately 200 AD), an ancient TCM book. Musk has been listed in the Chinese Pharmacopoeia for the treatment of stroke, tumors, traumatic injury, and cardiopathy with an oral dose of 0.03-0.1 g/day. In addition to being used as medicine, musk is also used as a spice base in East Asia [120].

Musk is rare and expensive. Thus, artificial musk has been studied based on the chemical composition and pharmacological effects of natural musk to protect wild musk sources. The results showed that artificial musk and natural musk have the same pharmacological activity [121]. In 1993, the Ministry of Health approved the trial production of artificial musk as a new Chinese medicine alternative to natural musk. Wang used an animal model of focal CI/RI and subarachnoid hemorrhage and found that the oral administration of low-dose artificial musk $(10 \mathrm{mg} / \mathrm{kg})$ could considerably improve the behavioral score and cerebral infarction volume of rats with transient CI/RI [122].

The chemical constituents of musk include steroids, lipids, peptides, and macrocyclic musk compounds with pharmaceutical activities, such as antitumor, antiulcer, antiinflammatory, adrenergic stimulation, and androgen-like effects [123].

Muscone is the most important monomer in musk. Muscone has a neuroprotective effect against stroke injury by inhibiting apoptosis in the brain. Muscone has neuroprotective effect on stroke injury by inhibiting apoptosis of brain cells. The protective effect of Muscone on cerebral ischemia depends on the activation of PI3K/Akt signaling pathway. $\mathrm{PI} 3 \mathrm{~K} /$ Akt signaling pathway, as the central mediator of neural stem cell signal transduction, plays an important role in the proliferation and differentiation of neural stem cells [124]. Muscone can prevent PC12 cells and cortical neurons from damage after various injuries, and inhibit glutamate induced apoptosis of PC12 cells and cortical neurons. Wei reported that Muscone may be a small active molecule with neuroprotective properties, and inhibition of apoptosis and Fas is an important mechanism of Muscone induced neuroprotection [99]. 
The MCAO rat model was established by a transient filament method and treated with musk ketone $(0.9$ or $1.8 \mu \mathrm{M})$. Next, an in vitro oxygen-glucose deprivation cell model was established to study the effect of musk ketone on the proliferation and differentiation of neural stem cells (NSCs). The results showed that the protective effect of muscone on cerebral ischemia depends on the activation of the PI3K/Akt signaling pathway. The PI3K/Akt signaling pathway, as a central mediator of signal transduction in NSCs, plays an important role in the proliferation and differentiation of NSCs [100]. Cell viability assays and gas chromatography-mass spectrometry were used to identify the active small molecules in XingNaoJing, which is a well-known Chinese medicine prescribed for the effective treatment of stroke. Studies have shown that muscone is the active compound that prevents damage in PC12 cells and cortical neurons following various injuries and inhibits the glutamate-induced apoptotic death of PC12 cells and cortical neurons. Wei's results demonstrated that muscone may be a small active molecule with neuroprotective properties, and the inhibition of apoptosis and Fas is an important mechanism of muscone-induced neuroprotection [99].

\subsection{Salvia miltiorrhiza}

Salvia miltiorrhiza is the dried root and rhizome of Salvia miltiorrhiza Bge. Salvia miltiorrhiza is one of the most popular Chinese materia medicines and is grown in the hilly areas of West, Southwest, and Southeast China. Numerous pharmaceutical forms of Salvia miltiorrhiza, including tablets, capsules, granules, injectables, oral liquids, sprays, and dripping pills, are commercially available in China [100]. Among all of the available forms, the Fufang Salvia miltiorrhiza tablet and Fufang Salvia miltiorrhiza dripping pill are the two most widely used products in China and have been officially listed in the Chinese Pharmacopoeia. The Fufang Salvia miltiorrhiza dripping pill has also been registered as a drug in several countries, including Vietnam, Russia, Cuba, the Korean Republic, and Saudi Arabia. This medicine has been used to treat stroke (since 1970), angina, and heart attack and is used as an antihypertensive and sedative. The SCED can alleviate cerebral ischemic injury, and its mechanism of action is related to the inhibition of thrombosis and platelet aggregation and activation of the PLC/PKC pathway [125].

The chemical components of Salvia miltiorrhiza are lipophilic and hydrophilic [100]. The liposoluble components are tanshinone, and the water-soluble components are salvianolic acids. In addition, Salvia miltiorrhiza also contains baicalin, ergosterol, ursolic acid, and other components. Tanshinone and salvianolic acid are the main bioactive and pharmacodynamic components of Salvia miltiorrhiza [126]. Salvianolic acid B is the most abundant and bioactive compound of the various Salvia miltiorrhiza phenolic acids extracted from Salvia miltiorrhiza mixtures. Salvianolic acid B can prevent brain ischemia-reperfusion injury in rats by reducing free radicals, improving energy metabolism, improving regional cerebral blood flow in the ischemic hemisphere, inhibiting platelet aggregation, and promoting the recovery of motor function after CI/RI.

Tanshinone can effectively resist ischemic injury to the central nervous system and protect neurons in the ischemic area. Park [127] used NeuN immunohistochemical analysis and F-J B histofluorescence staining to observe the protective effect of tanshinone I on ischemia-reperfusion injury in CA1 pyramidal neurons in gerbils. The results showed that tanshinone I pretreatment could protect against ischemia-induced neuronal death in the CA1 area by increasing or maintaining endogenous inflammatory cytokines. Tanshinone IIB has a protective effect against brain injury in rats. An intraperitoneal injection of 5 or $25 \mathrm{mg} / \mathrm{kg}$ tanshinone IIB could substantially reduce the infarct volume, brain injury, and apoptosis in rats with MCAO [128]. In addition, tanshinone IIA can play an important neuroprotective role in an animal model of ischemic brain injury by inhibiting inflammation, oxidative stress, and apoptosis [129].

Tanshinone can effectively resist ischemic injury of central nervous system and protect neurons in ischemic area. Park [127] reported that tanshinone I preconditioning can protect CA1 area ischemia-induced neuronal death by increasing or maintaining endogenous inflammatory cytokines. Tanshinone IIB can significantly reduce the infarct volume, brain injury and apoptosis in MCAO rats [128]. In addition, tanshinone IIA can play an important neuroprotective role in the animal model of ischemic brain injury by inhibiting inflammation, oxidative stress and apoptosis [129]. There are two main metabolic pathways of tanshinone, (a) hydroxylation, dehydrogenation, oxidation and furan ring cleavage of tanshinone, (b) Tanshinone is first metabolized to dehydro tanshinone, then hydroxylation, methoxylation, oxidation and furan ring cleavage are carried out on its molecule [130].

Salvia miltiorrhiza and Carthamus tinctorius are valued Chinese material medicines for the treatment of cardiovascular and cerebrovascular diseases and have multiple pharmacological effects, such as anti-inflammatory and antioxidant effects. Danhong injection combined with Salvia miltiorrhiza and Honghua has been widely used in clinical practice to treat patients with cerebrovascular disease [111].

\section{Chemical components of traditional medicines}

Some chemical compounds in Chinese material medicine are also effective in the treatment of ischemic stroke. In this section, we introduce some chemical components in detail. The chemical structures of these compounds are shown in Fig. 8.

\subsection{3-N-Butylphthalide (NBP)}

NBP, a family of compounds initially isolated from the seeds of Apium graveolens Linn., has shown considerable neuroprotective effects. NBP is composed of the optical isomers 1-3-N-butylphthalide (1-NBP) and d-3-N-butylphthalide (dNBP). In addition, dl-3-N-butylphthalide (Dl-NBP) is syn- 


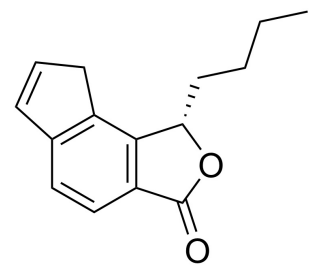

1-3-N-Butylphthalide<smiles>CCCC[C@H]1OC(=O)c2ccccc21</smiles>

d-3-N-Butylphthalide<smiles>CCCCC1OC(=O)c2ccccc21</smiles>

Dl-3-N-Butylphthalide

3-N-Butylphthalide (MF: $\mathrm{C}_{12} \mathrm{H}_{14} \mathrm{O}_{2}$ Compound CID: 61361)<smiles>O=C(O)[C@H]1O[C@@H](Oc2cc3oc(-c4ccc(O)cc4)cc(=O)c3c(O)c2O)[C@H](O)C(O)[C@@H]1O</smiles>

Scutellarin (MF: $\mathrm{C}_{21} \mathrm{H}_{18} \mathrm{O}_{12}$ Compound CID: 185617)<smiles>O=C(O)/C=C/c1ccc(O)c(O)c1</smiles>

Caffeic acid (MF: $\mathrm{C}_{9} \mathrm{H}_{8} \mathrm{O}_{4}$ Compound CID: 689043)<smiles>OC[C@H]1O[C@H](OCCc2ccc(O)cc2)[C@H](O)[C@@H](O)[C@@H]1O</smiles>

Salidroside (MF: $\mathrm{C}_{14} \mathrm{H}_{20} \mathrm{O}_{7}$ Compound CID: 159278)<smiles>O=C(O)c1cc(O)c(O)c(O)c1</smiles>

Gallic acid (MF: $\mathrm{C}_{7} \mathrm{H}_{6} \mathrm{O}_{5}$ Compound CID: 370 )

Fig. 8. The structure of the main chemical compounds in common use. The chemical structures of compounds were derived from PubChem (https: //pubchem.ncbi.nlm.nih.gov/).

thesized from 1-NBP. In 2002, 1-NBP was approved by the Food and Drug Administration of China for the treatment of ischemic stroke [131].

$\mathrm{Xu}$ [132] reported that 1-nbp can reduce the number of glial fibrillary acidic protein positive astrocytes induced by chronic cerebral ischemia, and has a protective effect on hippocampal injury induced by chronic cerebral ischemia. Li [133] reported that l-nbp treatment can significantly reduce ischemic brain injury and promote the early recovery of neurological function in patients with ischemic stroke. This effect may be related to the transformation of M1 microglia/macrophage to M2 phenotype. Sun [134] reported that Dl-NBP could significantly increase the number and length of CST fibers in denervated cervical spinal cord, significantly increase the expression levels of PSD95 and vglut1 , increase the number of BrdU+/DCX+ cells in the SVZ; and markedly reduce Rho- $\mathrm{A}+$, rock + , Nogo- $\mathrm{A}+$, and nogo$\mathrm{r}+$ cells in the peripheral cortex.

Studies focused on human metabolism and the pharmacokinetics of NBP showed that NBP is safe for human usage and undergoes oxidation by cytochrome P450 after oral administration to form 23 identified metabolites, among which 10-keto-NBP, 3-hydroxy-NBP, 10-hydroxy-NBP, and NBP11-oic acid are considered the major metabolites [135].

\subsection{Scutellarin}

Scutellarin is an herbal flavonoid glucuronide with multiple pharmacological activities and is the main active component of Erigeron breviscapus (Vant.) Hand-Mazz. Scutellarin has been used clinically to treat stroke, myocardial infarction, and diabetic complications owing to its multiple beneficial effects, such as antioxidant, anti-inflammation, vascular relaxation, antiplatelet, anticoagulation, and myocardial protection effects [136]. Scutellarin inhibits oxidative damage by directly scavenging free radicals and NO produced during oxidative damage [137]. Apoptosis was inhibited by inhibiting PARP-dependent mitochondrial dysfunction and the translocation of apoptosis-inducing factors [138]. Scutellarin $(50 \mu \mathrm{g} / \mathrm{L})$ significantly reduced the increase in intracellular calcium induced by $\mathrm{H}_{2} \mathrm{O}_{2}$ in the cortical neuron injury model induced by $\mathrm{H}_{2} \mathrm{O}_{2}$ and alleviated the cytotoxicity caused by free radicals by preventing intracellular calcium overload [139]. Therefore, the neuroprotective effect of scutellarin may be due to its antioxidant, antiapoptotic and calcium channel-protective effects. In addition, Yuan et al. [140] reported that scutellarin contributed to the clinical treatment of cerebral ischemia by inhibiting microglial activation and alleviating the symptoms of neuroinflammation. Du et al. [141] demonstrated that scutellarin activated the endothelial cGMP-activated protein kinase G (PKG) pathway to protect cerebrovascular endothelial cells. Furthermore, 
scutellarin prevented learning and memory defects in a rat model of Alzheimer's disease by reducing oxidative stress and inflammation [142].

Scutellarin is minimally toxic or nontoxic in rodents. The $50 \%$ lethal dose of scutellarin could not be determined. Similar to many plant-derived flavonoid glucuronides, scutellarin has low solubility in body fluids, unfavorable bioavailability, and a short half-life in mammalian systems. In addition, the hydrolyzed form, scutellarein, is relatively easily absorbed into the blood and can be metabolized into methylated, sulfated, or glucuronidated forms [143].

\subsection{Caffeic acid (3,4-dihydroxycinnamic acid, CA)}

$\mathrm{CA}$ is a phenolic compound that is widely distributed in medicinal plants, such as Perillafrutescens, Dendranthema morifolium (Ramat.) Tzvelev, Patrinia villosa, and Taraxacum mongolicum Hand.-Mazz. CA is an inhibitor of 5-LO and an intriguing compound because it possesses various pharmacological activities, including antibacterial, antiviral, antioxidant, anti-inflammatory, antiatherosclerotic, immunostimulatory, antidiabetic, cardioprotective, antiproliferative, hepatoprotective, anticancer, and anti-hepatocellular carcinoma activities [144].

Liang [145] studied the effect of CA on global CI/RI by biochemical and histological analyses. The results showed that CA has a remarkable protective effect against global $\mathrm{CI} / \mathrm{RI}$ in rats. This neuroprotective effect may be mediated by the inhibition of 5-LO. Yang [146] injected aluminum (5.0 $\mu \mathrm{g}$ aluminum, $2.0 \mu \mathrm{L}$, once a day for 5 days) into the lateral ventricle to induce brain injury in mice. The results showed that CA antagonized the aluminum-induced increase in brain malondialdehyde levels and the decrease in ChAT expression; CA downregulated the overexpression of APP and amyloid beta protein, as well as 5-LOX mRNA and protein expression, in a dose-dependent manner.

The pharmacokinetic effect of CA begins with its ingestion as a bound form (esterified) and its absorption upon arriving in the stomach. CA is subjected to three main types of enzymatic conjugation (known as detoxification), namely, methylation, sulphation, and glucuronidation, immediately after absorption through the action of sulfotransferase enzymes, UDP-glucotransferases, and catecholo-methyltransferases, respectively [147].

\subsection{Salidroside}

Salidroside (Sal) is a bioactive extract principally from traditional herbal medicine such as Rhodiola crenulata (Hook. f. et Thoms.) H. Ohba., which has been commonly used for hundreds of years in Asia countries. Sal is mainly isolated from Crassulaceae and others plants such Oleaceae, Labiatae and Loganiaceae [148]. Previous studies revealed that Sal possessed a wide range of biological activities, such as anti-inflammatory, anti-apoptotic, anti-hypoxic, antidepressive and anti-oxidative effects [149-151], for treatment of Alzheimer's disease, Parkinson's disease, Huntington's disease, epilepsy, cancer, diabetes, liver damage and ad- diction [152-154].

Recently, accumulating researches has shown that Sal could be used as an effective neuroprotection agent due to its significant effect on preventing neuronal injury after cerebral ischemia. Sal can inhibit excitotoxicity, oxidative stress, inflammation, apoptosis and BBB injury. It was found that Sal induced activity of SOD, GSH-Px, and GST in MCAO models, significantly attenuating cerebral I/R injury [155]. By inhibiting the activation of MMP-9 (a member of MMPs) and reversing the decrease of tight junction proteins such as claudin-5 and occludin, it shows the improvement of BBB injury in experimental stroke rat model [156]. Xia Chen [157] reported Sal efficiently protected hippocampal neurons against glutamate-induced excitotoxicity by inhibiting excessive $\mathrm{Ca}^{2+}$ influx and neuronal apoptosis. In addition, numerous evidence has showed that Sal significantly reduce level of these proinflammatory cytokines and chemokines, such as tumor necrosis factor- $\alpha$ (TNF- $\alpha$ ), interleukine-2 (IL-2), interleukine-6 (IL-6), interleukine- 8 (IL-8), interleukine- $1 \beta$ (IL-1 $\beta$ ), MCP-1 and MIP- $1 \alpha$, in tissue or serum of experimental model of ischemic stroke [158, 159], and the number of terminal deoxynucleotidyl transferase dUTP nick end labelling (TUNEL)-positive cells in the peri-infarct zone of MCAO rats with $1 \mathrm{~h}$ reperfusion[160].

Sal, a principal physiologically active constituent from Rhodiola genus herb drug which has been widely verified to be no toxicity or less side effects in a multitude of animal experiments and clinical trials [161], is recognized as a safe natural ingredient agent similarly. The results of pharmacokinetic studies showed that Sal was widely distributed into multiple tissues and organs after entering circulation system, and can still converge in brain spite of keeping a low-rise concentration [162].

\subsection{Gallic acid}

Gallic acid (GA), a class of phenolic compounds, also known as 3,4,5- trihydroxybenzoic acid, is a naturally occurring secondary metabolite found in various plants, vegetables, nuts and fruits [163]. The pure GA are white or light brown needle-like crystals or powders with melting points of $235-240{ }^{\circ} \mathrm{C}$ (decomposition). Among many polyphenols, GA is a low molecular weight tri-phenolic compound with excellent anti-inflammatory and anti-oxidative activities [164]. In addition, GA also has several evident pharmacological effects including anti-tumor, anti-bacterial, antidiabetes, anti-obesity, anti-microbial and anti-cardio cerebral ischemia [165-168].

As a histone acetyltransferase inhibitor, GA could counteract amyloid-induced neurotoxicity by selectively suppressing NF- $\kappa \mathrm{B}$ activation in the animal model of Alzheimer's disease [169]. Furthermore, Liu et al. [170] indicated that GA could recede $\alpha$-nucleoprotein, GFAP and ED-1 proteins, resulting in suppressed IL-1, NO and iNOS levels in LPSsimulated Parkinson's disease. In addition, it has been reported that GA can directly affect the binding of cypd and ANT-1 and the phosphorylation level of ERK, inhibit the 
expression of cypd, increase the opening threshold of mitochondrial MPTP, and effectively resist the injury of nerve cells in the pathological process of ischemic stroke [171].

Promisingly, toxicity studies have shown that GA scarcely has obvious toxicity or side effects in a variety of animal experiments and clinical trials [172]. According to pharmacokinetic studies, GA is firstly absorbed by the gastrointestinal tract, and then mainly distributed in the kidneys. And it is metabolized by the liver and excreted by the kidney, respectively. Noteworthily, methylation, glucoside acidification and sulfated products are the main forms of GA in vivo. In brief, the absorption and elimination of GA after oral administration are fast, while the structural optimization or dosage form adjustment of GA is beneficial to increase its bioavailability [173-175].

\section{Conclusions}

Modern medicine [176] holds that the main pathogenesis of cerebral infarction is atherosclerosis and plaque deposition on the blood vessel wall, which leads to lumen infarction, decreased vascular elasticity, increased blood viscosity, slowed blood flow, plaque shedding, and arterial and vascular blockage and results in a series of clinical changes, such as ischemia, hypoxia, and the degradation and necrosis of blood and brain tissues. Therefore, clinical treatments focus on neuroprotection, anticoagulation, thrombolysis, increasing blood flow, and lowering blood pressure. However, many patients lose the opportunity for thrombolytic therapy because of the limitation of the treatment window. Anticoagulant and antiplatelet drugs, such as aspirin, clopidogrel and prasugrel, are commonly used clinical drugs. Among them, aspirin inhibits the formation of TXA2, and clopidogrel and prasugrel inhibit the P2Y12 (ADP) receptor to prevent thrombus formation [177]. Although these drugs have low prices and notable curative effects, they are prone to hemorrhagic injuries during treatment, such as secondary hemorrhage from infarct focus and visceral hemorrhage [178]. The MATCH trial included 7599 subjects from 28 countries, and the result was that clopidogrel + aspirin were used for some subjects with ischemic stroke, transient ischemic attack, and bleeding adverse events. The frequent increase occurred, endangering patient lives, and no good results were obtained [179]. Chinese medicines have a great advantage in the treatment of stroke compared with modern medicine [180] because of the advantage of prescriptions. The complementary therapeutic effects of different prescriptions and specific effects of TCM are conducive to the smooth recovery after stroke under the guidance of the overall concept and theory of syndrome differentiation and treatment. Moreover, traditional medicines have stable and long-lasting effects on cerebral ischemia. Furthermore, traditional medicines can greatly reduce the side effects and adverse reactions of drugs and ensure the safety of clinical medication. However, traditional medicine decoctions are not easy to extract completely because of the large number of medicinal components, and the fat-soluble and insoluble components are decocted in water. Therefore, the absorption and the effect are slow.

Traditional Chinese patent medicines have been widely used clinically with the development of the modern pharmaceutical industry [181]. Compared with traditional Chinese medicine decoctions, Chinese patent medicines are easy to take and carry. Furthermore, different traditional medicines use different processing methods, and the effective substances are completely extracted. Traditional Chinese patent medicines have certain effects on treating ischemic stroke by improving daily life, the symptoms of neurological deficits and TCM syndromes. Some biological indicators, such as plasma NO levels, serum tumor factors, and circulating endothelial cell levels, can also explain their mechanism of action [182]. At present, traditional Chinese patent medicines can assist Western medicine in preventing vascular spasms, improving the cerebral vascular supply, and generally improving the therapeutic effect in patients with stroke [183].

This article summarizes and identifies the name, original species, family, medicinal parts, traditional use, pharmacological effects and other aspects of traditional medicines for the treatment of ischemic stroke. The results showed that most of these traditional medicines are botanical medicinal materials and are distributed among 132 families. Leguminosae was the most common. We found several traditional medicines that are commonly used to treat ischemic stroke, such as L. chuanxiong, safflower, Angelica sinensis, and musk, through literature searching and data mining. Pharmacology, phytochemistry, metabolomics and clinical trials were performed to evaluate the biological activity and clarify the mechanism of action. In addition, special attention should be paid to several active compounds isolated from the most commonly used medicines. We believe that ligustrazine, ferulic acid, hydroxysafflor yellow A, and LIG may be good and promising therapeutic candidates for the treatment of ischemic stroke because they have the neuroprotective effects and are present in high concentrations in corresponding species. In the future, we can find new perspectives for the treatment of ischemic stroke by studying the effective components and mechanisms of relevant preparations and traditional medicines. For example, Li explored the use of traditional medicines to treat ischemic stroke in the context of the mitochondrial permeability transition pore and found that traditional medicines inhibit neuronal apoptosis induced by excessive opening of the mitochondrial permeability transition pore [184]. Furthermore, the effective components in the preparations and traditional medicines were extracted and further studied, and these components may become potential drugs for the treatment of ischemic stroke. In addition, in ethnic medicine, there are many traditional medicines that are not common traditional Chinese medicines, such as Haematitum, Hydragyrum and Nardostachys jatamansi (D. Don) DC. These traditional medicines increase the probability of discovering novel effective components and are also conducive to the development of more stable and safe new drugs. 


\section{Abbreviations}

TCM, traditional Chinese medicine; WHO, World Health Organization; RNS, reactive nitrogen species; ROS, reactive oxygen species; SOD, superoxide dismutase; CAT, catalase; GSH-PX, glutathione peroxidase; GSH, glutathione; MDA, Malondialdehyde; NO, nitric oxide; 3-NT, 3nitrotyrosine; NMDA, N-methyl-D-aspartic acid; MLB, Magnesium lithospermate B; TNF- $\alpha$, tumor necrosis factora; MCP-1, monocyte chemotactic protein-1; MCAO, middle cerebral artery occlusion; KRS, kaempferol-3-o-rutinoside; KGS, kaempferol-3-o-glucoside; AO, Angelica sinensis essential oil; 1-NBP, 1-3-N-butylphthalide; d-NBP, d-3-Nbutylphthalide; Dl-NBP, dl-3-N-butylphthalide; CA, 3,4dihydroxycinnamic acid; NVU, neurovascular unit; Nrf2, Nuclear factor erythroid 2-related factor 2; HO-1, heme oxygenase-1; MF, Mangiferin; CI/RI, cerebral ischemiareperfusion injury; SCED, supercritical $\mathrm{CO}_{2}$ extract from Salvia miltiorrhiza; LC3-I, cytoplasmic LC3; LC3-II, membrane LC3; BBB, blood-brain barrier; NSCs, neural stem cells; GA, Gallic acid; Sal, Salidroside.

\section{Author contributions}

MX, RXW and ZW designed the review. XLL, YSZ, JYL, $\mathrm{KF}$, YL collects information. RXW arranges data. MX wrote the manuscript. ZW helped prepare the figures and revised the manuscript. All authors discussed, edited and approved the final version.

\section{Ethics approval and consent to participate Not applicable.}

\section{Acknowledgment}

We thank Chengdu University of Traditional Chinese Medicine for providing us with a research platform.

\section{Funding}

This work was supported by National Natural Science Foundation of China (81102895), China Postdoctoral Science Foundation (2012M511916), Sichuan application basic research plan (2016JY0017).

\section{Conflict of interest}

The authors declare no conflict of interest.

\section{Supplementary material}

Supplementary material associated with this article can be found, in the online version, at https://www.imrpress.com/j ournal/JIN/21/1/10.31083/j.jin2101026.

\section{References}

[1] Yu ZH, Luo LS, Li M, Wei JH, Meng RT, Yuan RX. The severity of stroke burden in China from a global perspective. Public Health and Preventive Medicine. 2016; 27: 1-5. (In Chinese)

[2] Ma Y. Study on medical expenses and influencing factors of stroke patients in urban residents of China [Doctoral thesis]. Beijing: Beijing University of Chinese Medicine. 2018. (In Chinese)
[3] Tang WH, Zhang BB, Ding YB. Observation on the curative effect of early treatment of acute ischemic stroke with combination of acupuncture and medicine. Journal of Cardiovascular and Cerebrovascular Diseases with Integrated Traditional Chinese and Western Medicine. 2018; 16: 137-139. (In Chinese)

[4] Hung I, Hung Y, Wang L, Hsu S, Chen H, Tseng Y, et al. Chinese herbal products for ischemic stroke. The American Journal of Chinese Medicine. 2015; 43: 1365-1379.

[5] Hasan TF, Todnem N, Gopal N, Miller DA, Sandhu SS, Huang $\mathrm{JF}$, et al. Endovascular thrombectomy for acute ischemic stroke. Current Cardiology Reports. 2019; 21: 112.

[6] Zhen YL, Ding CJ, Sun JQ, Wang YN, Li S, Dong LY. Activation of the calcium-sensing receptor promotes apoptosis by modulating the JNK/p38 MAPK pathway in focal cerebral ischemiareperfusion in mice. American Journal of Translational Research. 2016; 8: 911-921.

[7] Liu T, Song F, Lu DY, Dong L, Wu Q, Liu ZY, et al. Anti-oxidation and anti-apoptosis mechanism of xinshao formula on cerebral ischemia reperfusion injury. China Journal of Chinese Materia Medica. 2018; 43: 3519-3524. (In Chinese)

[8] Sun S, Chen X, Gao Y, Liu Z, Zhai Q, Xiong L, et al. Mn-SOD upregulation by electroacupuncture attenuates ischemic oxidative damage via CB1R-mediated STAT3 phosphorylation. Molecular Neurobiology. 2016; 53: 331-343.

[9] Kraus A, Roth H, Kirchgessner M. Supplementation with vitamin $\mathrm{C}$, vitamin $\mathrm{E}$ or $\beta$-carotene influences osmotic fragility and oxidative damage of erythrocytes of zinc-deficient rats. The Journal of Nutrition. 1997; 127: 1290-1296.

[10] Yan A, Xie YL. Effect of angelicae sinensis radix polysaccharide on oxidative stress level and inflammatory cytokine expression of brain tissues in rats with cerebral ischemia reperfusion injury. Chinese Journal of experimental Traditional Medical Formulae. 2018; 24: 131-135. (In Chinese)

[11] Yang C, Yen T, Hsu C, Thomas P, Sheu J, Jayakumar T. Multitargeting andrographolide, a novel NF- $x \mathrm{~B}$ inhibitor, as a potential therapeutic agent for stroke. International Journal of Molecular Sciences. 2017; 18: 1638.

[12] Hobbs AJ, Fukuto JM, Ignarro LJ. Formation of free nitric oxide from 1-arginine by nitric oxide synthase: direct enhancement of generation by superoxide dismutase. Proceedings of the National Academy of Sciences of the United States of America. 1994; 91: 10992-10996.

[13] Nakamura T, Prikhodko OA, Pirie E, Nagar S, Akhtar MW, Oh C, et al. Aberrant protein S-nitrosylation contributes to the pathophysiology of neurodegenerative diseases. Neurobiology of Disease. 2015; 84: 99-108.

[14] Cheng XN, Yang AL, Zhao YN, Tu PF, Huang WZ, Zhu JB, et al. Research progress on pathogenesis of ischemic stroke and traditional chinese medicine commonly used for treatment of ischemic stroke. China Journal of Chinese Materia Medica. 2019; 44: 422432. (In Chinese)

[15] Shang Y, Tian J, Hou M, Xu X. Progress on the protective effect of compounds from natural medicines on cerebral ischemia. Chinese Journal of Natural Medicines. 2014; 11: 588-595. (In Chinese)

[16] Han F, Fukunaga K. Melatonin ameliorates iscbemic-like injuryevoked nitrosative stress: involvement of HtrA2/PED pathways in endothelial cells. Journal of Pineal Research. 2011; 50: 281-291.

[17] Behravan E, Razavi BM, Hosseinzadeh H. Review of plants and their constituents in the therapy of cerebral ischemia. Phytotherapy Research. 2014; 28: 1265-1274.

[18] Li Z, Yulei J, Yaqing J, Jinmin Z, Xinyong L, Jing G, et al. Protective effects of tetramethylpyrazine analogue Z-11 on cerebral ischemia reperfusion injury. European Journal of Pharmacology. 2019; 844: 156-164.

[19] Luo C, Xu X, Wei X, Feng W, Huang H, Liu H, et al. Natural medicines for the treatment of fatigue: Bioactive components, pharmacology, and mechanisms. Pharmacological Research. 2019; 148: 104409. 
[20] Kobayashi T, Mori Y. $\mathrm{Ca}^{2+}$ channel antagonists and neuroprotection from cerebral ischemia. European Journal of Pharmacology. 1999; 363: 1-15.

[21] Dirnagl U, Iadecola C, Moskowitz MA. Pathobiology of ischaemic stroke: an integrated view. Trends in Neurosciences. 1999; 22: 391-397.

[22] Chen M, Lu T, Chen X, Zhou Y, Chen Q, Feng X, et al. Differential roles of NMDA receptor subtypes in ischemic neuronal cell death and ischemic tolerance. Stroke. 2008; 39: 3042-3048.

[23] Ma R, Ellis KJ, Yasumura S, Shypailo RJ, Pierson RN. Total bodycalcium measurements: comparison of two delayed-gamma neutron activation facilities. Physics in Medicine and Biology. 1999; 44: N113-N118.

[24] Hosseinzadeh H, Sadeghnia HR. Safranal, a constituent of Crocus sativus (saffron), attenuated cerebral ischemia induced oxidative damage in rat hippocampus. Journal of Pharmacy \& Pharmaceutical Sciences. 2005; 8: 394-399.

[25] Zaleska MM, Mercado MLT, Chavez J, Feuerstein GZ, Pangalos MN, Wood A. The development of stroke therapeutics: promising mechanisms and translational challenges. Neuropharmacology. 2009; 56: 329-341.

[26] Zhang X, Zhang Y, Tang S, Yu L, Zhao Y, Ren Q, et al. Pien-TzeHuang protects cerebral ischemic injury by inhibiting neuronal apoptosis in acute ischemic stroke rats. Journal of Ethnopharmacology. 2018; 219: 117-125.

[27] Yin F, Zhou H, Fang Y, Li C, He Y, Yu L, et al. Astragaloside IV alleviates ischemia reperfusion-induced apoptosis by inhibiting the activation of key factors in death receptor pathway and mitochondrial pathway. Journal of Ethnopharmacology. 2019; 248: 117125.

[28] Cao Z, Quan W, Hou S, Guo C, Ma S, Zhang W, et al. The natural therapeutic magnesium lithospermate $B$ potently provides neuroprotective effects on cerebral ischemia/reperfusion injury in rats. Journal of Ethnopharmacology. 2015; 162: 191-198.

[29] Peng T, Jiang Y, Farhan M, Lazarovici P, Chen L, Zheng W. Anti-inflammatory effects of traditional chinese medicines on preclinical in vivo models of brain ischemia-reperfusion-injury: prospects for neuroprotective drug discovery and therapy. Frontiers in Pharmacology. 2019; 10: 204.

[30] He W, Chen W, Zhou Y, Tian Y, Liao F. Xanthotoxol exerts neuroprotective effects via suppression of the inflammatory response in a rat model of focal cerebral ischemia. Cellular and Molecular Neurobiology. 2013; 33: 715-722.

[31] Zhao X, Li J, Sun H. CD200-CD200R interaction: an important regulator after stroke. Frontiers in Neuroscience. 2019; 13: 840.

[32] Taylor RA, Sansing LH. Microglial responses after ischemic stroke and intracerebral hemorrhage. Clinical \& Developmental Immunology. 2013; 2013: 746068.

[33] Cheng C, Lee Y. Anti-inflammatory effects of traditional chinese medicines against ischemic injury in in vivo models of cerebral ischemia. Evidence-Based Complementary and Alternative Medicine. 2016; 2016: 5739434.

[34] Zhong ZZ, Xu QP. Platelet and ischemic stroke and evaluation of antiplatelet drugs. Chinese Journal of Pharmacy. 2000; 10: 652655. (In Chinese)

[35] Faure M, Castilloux A, Lillo-Le-Louet A, Bégaud B, Moride Y. Secondary stroke prevention: a population-based cohort study on anticoagulation and antiplatelet treatments, and the risk of death or recurrence. International Journal of Clinical Pharmacology and Therapeutics. 2019; 107: 443-451.

[36] Yu YF, Dong GS. Leukocytes, platelets, thrombin and cerebral microcirculation disturbance. Foreign Medicine: Cerebrovascular Diseases. 2001; 4: 222-224.

[37] Chen C, Li T, Zhao Y, Qian Y, Li X, Dai X, et al. Platelet glycoprotein receptor $\mathrm{Ib}$ blockade ameliorates experimental cerebral ischemia-reperfusion injury by strengthening the blood-brain barrier function and anti-thrombo-inflammatory property. Brain, Behavior, and Immunity. 2018; 69: 255-263.

[38] Zhang W, Han L, Hu, JF, Chen NH. Research progress on pro- tective mechanism of osthol against cerebral ischemia injury. Acta Neuropharmacology. 2012; 02: 42-47.

[39] Wang P, Guan Y, Du H, Zhai Q, Su D, Miao C. Induction of autophagy contributes to the neuroprotection of nicotinamide phosphoribosyltransferase in cerebral ischemia. Autophagy. 2012; 8: 77-87.

[40] Gao L, Jiang T, Guo J, Liu Y, Cui G, Gu L, et al. Inhibition of autophagy contributes to ischemic postconditioning-induced neuroprotection against focal cerebral ischemia in rats. PLoS ONE. 2012; 7: e46092.

[41] Levine B, Sinha SC, Kroemer G. Bcl-2 family members: Dual regulators of apoptosis and autophagy. Autophagy. 2008; 4: 600-606.

[42] Liu Y, Levine B. Autosis and autophagic cell death: the dark side of autophagy. Cell Death and Differentiation. 2014; 22: 367-376.

[43] Zang R, Yang JP, Guo T, Chu X, Zhang XY, Wu YM, et al. Schisandrin a improves neuroprotection by induction of neuronal autophagy in ischemic penumbra after stroke. Chinese Journal of Biochemistry and Molecular Biology. 2020; 36: 544-551. (In Chinese)

[44] Zhou S, Qiao B, Chu X, Kong Q. Oxymatrine attenuates cognitive deficits through SIRT1-mediated autophagy in ischemic stroke. Journal of Neuroimmunology. 2019; 323: 136-142.

[45] Li YX, Liu ZQ, Li Y, Tan TY, Bai X, Liu MQ, et al. Research progress of neurovascular unit in ischemic stroke. Chinese Journal of Geriatric Heart. Brain and Vessel Diseases. 2019; 21: 111-114.

[46] Li YF, Liu K, Ni YQ, Yang ZH, Fu WS. Effects of ligustrazine on blood-brain barrier and claudin-5 expression in rat after cerebral ischemia and reperfusion. Journal of China Medical University. 2013; 42: 511-514. (In Chinese)

[47] Wen Y, Zhu CH, Wang LN, Ji H, Liu Y. Mechanism of tanshinoneIIA protecting blood-brain barrier in focal cerebral ischemia of rats. Journal of Hebei Medical University. 2014; 35: 869-872. (In Chinese)

[48] Zhang YQ, Li H, Xu W, Xu W, Huang M, Chu KD, et al. Effects of Gualou Guizhi granule on blood brain barrier permeability and neuroprotection in cerebral ischemia-reperfusion injury rat. China Journal of Traditional Chinese Medicine and Pharmacy. 2015; 30: 1410-1417. (In Chinese)

[49] Zhang J, Long JF, Zhou HY, Zhang QX, Zhao H, Wang L, et al. Effect of active fraction from Huanglian Jiedu decoction on activation of astrocytes and expression. Chinese Traditional and Herbal Drugs. 2014; 45: 1876-1882. (In Chinese)

[50] Fan Y, Wu XG, Zhao HX, Shang YZ. Effects of scutellaria barbata flavonoids on abnormal expression of NOS, HSP70 and apoE induced by A $\beta 25-35$ in rat astrocytes. Chinese Journal of Pathophysiology. 2014; 30: 359-363. (In Chinese)

[51] Ye ZG, Wang ZM, Wang YS, Wang JH, Liang GG, Du GY, et al. Pharmacological characteristics and safety evaluation of cinnabar and realgar in Angong Niuhuang pills. Chinese Journal of Traditional Chinese Medicine. 2004; 19: 102-105. (In Chinese)

[52] Wang JH, Ye ZG. Research status of Angong Niuhuang pills. Chinese Journal of Traditional Chinese Medicine. 2004; 29: 119-122. (In Chinese)

[53] Wang JH, Ye ZG, Liang AH, Xue BY, Wang YS, Wang ZM, et al. Absorption and distribution of mercury and arsenic in Angong Niuhuang pill in normal and cerebral ischemia rats. Chinese Journal of Traditional Chinese Medicine. 2003; 28: 639-642. (In Chinese)

[54] Yang WQ, Reng YL, Guo KF, Zhu YX. Effects of Angong Niuhuang Pill on nitric oxide synthase and monoamine neurotransmitters in brain tissues of rats with acute cerebral hemorrhage. Journal of Emergency in Traditional Chinese Medicine. 2009; 18: 83-84. (In Chinese)

[55] Liu ZT, Liu J, Li JB, Liu YX. Protective effect of Angong Niuhuang Pill on experimental cerebral ischemia in rats. Journal of Cardiovascular and Cerebrovascular Diseases with Integrated Traditional Chinese and Western Medicine. 2011; 09: 710-712. (In Chinese)

[56] Fu ZH. Clinical observation of Angong Niuhuang pill in the treatment of dizziness in acute stage of stroke. New Chinese Medicine. 
1993; 025: 33-34. (In Chinese)

[57] Yu YF, Li XM, Sun Y, Wang XH. Clinical report of 53 cases of apoplexy treated by enema with Angong Niuhuang pill. Journal of Traditional Chinese Medicine.1993; 02: 33-34. (In Chinese)

[58] Zhu KJ, Sun JN, Ma CH, Geng Y. Effect of Aangong Niuhuang pill and heavy metal constituents on EcoG of brain damage caused by LPS in rats. China journal of Chinese Materia Medica. 2007; 32: 949-953.

[59] Lei Z, Peng F, Guan BH, Li X, Wu W, Cheng JB, Sheng JG. Whether metal element-containing herbal formula Angong Niuhuang Pill is safe for acute brains disorders. Biological Trace Element Research. 2015; 166: 41-48. (In Chinese)

[60] Xu WL, Sun WJ, Wang Z, Liu GL, Xu YM, Liang Y. Dose-effect relationship of Qishiwei Zhenzhu Pills against cerebral ischemicreperfusion injury in rats. Drugs \& Clinic. 2017; 32: 10-15.

[61] Xu M, Wu RX, Liang Y, Fu K, Zhou Y, Li XX, et al. Protective effect and mechanism of Qishiwei Zhenzhu pills on cerebral ischemia-reperfusion injury via blood-brain barrier and metabonomics. Biomed Pharmacother. 2020; 131: 110723.

[62] Li Y, Yi FS, Li TC, Du YZ. Determination of trace elements in Seventy-flavor pearl pills of tibetan medicine. Microelement Science in Guangdong Province. 2001; 8: 51-52. (In Chinese)

[63] Fu K, Xu M, Zhou Y, Li X, Wang Z, Liu X, et al. The Status quo and way forwards on the development of Tibetan medicine and the pharmacological research of tibetan materia Medica. Pharmacological Research. 2020; 155: 104688.

[64] An EJ, Suo YR. Advances in modern pharmacology of tibetan medicine Seventy-flavor pearl pills. Chinese Journal of Ethnic Medicine. 2004; 10: 33-35. (In Chinese)

[65] Wu LQQG. Experience in the treatment of 77 cases of Sa disease with Qishiwei zhenzhu pills. Chinese Journal of Ethnomedicine and Ethnopharmacy. 2010; 19: 98. (In Chinese)

[66] Cao JM. Pharmacology and clinical application of Ginkgo biloba leaves. Modern Journal of Integrated Traditional Chinese and Western Medicine. 2005; 14: 3171-3172. (In Chinese)

[67] Xie H, Wang JR, Yau LF, Liu Y, Liu L, Han QB, et al. Quantitative analysis of the flavonoid glycosides and terpene trilactones in the extract of ginkgo biloba and evaluation of their inhibitory activity towards fibril formation of $\beta$-amyloid peptide. Molecules. 2014; 19: 4466-4478.

[68] Wang SY. Therapeutic effect of Ginkgo biloba extract on cerebral ischemia. Tianjin Pharmacy. 2002; 14: 27-28. (In Chinese)

[69] Yuan DP, Fang TH, Xu L, Xu L. Effect of folium ginkgo tablet on MDA, SOD and AchE of vascular dementia. Journal of Nanjing University of Traditional Chinese Medicine.2004; 20: 40-41. (In Chinese)

[70] Cao JM. Overview of pharmacology and clinical application of Ginkgo biloba leaves. Modern Journal of Integrated Traditional Chinese and Western Medicine. 2005; 14: 3171-3172. (In Chinese)

[71] Liu SB, Li XZ, Ling CR, Wang YH, Wang M. Protective effect of Huatuo Zaozhuang Pill on myocardial infarction induced by myocardial ischemia-reperfusion in rats. New Chinese Medicine and Clinical Pharmacology. 2014; 25: 536-538. (In Chinese)

[72] Duan S, Wang T, Zhang J, Li M, Lu C, Wang L, et al. Huatuo Zaizao pill promotes functional recovery and neurogenesis after cerebral ischemia-reperfusion in rats. BMC Complementary and Alternative Medicine. 2017; 17: 19.

[73] Zhang JH, Yu LJ, Yang H, Hui Z, Jiang S, Chen L, et al. Huatuo Zaizao pill ameliorates cognitive impairment of APP/PS1 transgenic mice by improving synaptic plasticity and reducing $\mathrm{A} \beta$ deposition. BMC Complementary and Alternative Medicine. 2018; 18: 167.

[74] Liu Y, Luo ZM, Ji L, Gao L, Zhang Z, Zeng Z. Protective effect of Huatuo Zaizao Pill on focal cerebral ischemia injury in rats. Huaxi Pharmaceutical Journal. 2004; 19: 3. (In Chinese)

[75] Liu JG, Li ZW, Xu HM, Xu XS. Huatuo reconstruction pill prevents thrombosis and microcirculation disorders in experimental animals. Guangdong Medical Journal. 2000; 21: 368-370. (In Chinese)
[76] Li YY, Fan XA, Gong T, Feng YM. The progress of Xueshuan Xinmaining applied to cardiovascular disease. Western Journal of Traditional Chinese Medicine. 2017; 30: 143-145. (In Chinese)

[77] Liu JW, Zhang XT, Zhang C, Sai JY, Wang XL, Wang HD, et al. Effect of Xueshuan Xinmaining tablet on the whole gene expression profile of vascular endothelial cells. Journal of Cardiovascular and Cerebrovascular Diseases with Integrated Traditional Chinese and Western Medicine. 2013: 11: 576-579. (In Chinese)

[78] Han YX, Wang PF, Zhao M, Chen LM, Wang ZM, Liu XQ, et al. Chemical profiling of xueshuan xinmaining tablet by HPLC and UPLC-ESI-Q-TOF/MS. Evidence-Based Complementary and Alternative Medicine. 2018; 2018:2781597.

[79] Wang YH, Zhao XL, Liu XL. TCD monitoring effect of oral Xueshuanxinmaining on transient ischemic attack. Liaoning Journal of Traditional Chinese Medicine. 2005; 32: 1230-1231. (In Chinese)

[80] Yang CM, Liu B, Ju DY, Yu XF, Qu SC. Protective effect of Xueshuan Xinmaining capsules on experimental myocardial infarction in rats. Medical Journal of the Chinese people's Armed Police Forces. 2005; 352-354. (In Chinese)

[81] Cheng CY, Kao ST, Lee YC. Angelica sinensis extract protects against ischemia-reperfusion injury in the $\mathrm{T}$ hippocampus by activating p38 MAPK-mediated p90RSK/p-Bad and p90RSK/CREB/BDNF signaling after transient global cerebral ischemia in rats. Journal of Ethnopharmacology. 2020; 252: 112612.

[82] Tang NY, Liu CH, Hsieh CT, Hsieh CL. The anti-inflammatory effect of paeoniflorin on cerebral infarction induced by ischemiareperfusion injury in Sprague-Dawley rats. The American Journal of Chinese Medicine. 2010; 38: 51-64.

[83] Zhao QP, Cheng XL, Zhu YF, Zhu ZZ. The protective effects of $\mathrm{Mu}$-Xiang-You prescription on cerebral ischemia-reperfusion injury in rats by attenuat inflammatory factors. Journal of Ningxia Medical University. 2016; 38: 729-733. (In Chinese)

[84] Dong T, Chen N, Ma X, Wang J, Wen J, Xie Q, et al. The protective roles of L- borneolum, D- borneolum and synthetic borneol in cerebral ischaemia via modulation of the neurovascular unit. Biomedicine \& Pharmacotherapy. 2016; 102: 874-883.

[85] Sun YX, Tang Y, Wu AL, Liu T, Dai XL, Zheng QS, et al. Neuroprotective effect of liquiritin against focal cerebral ischemia/reperfusion in mice via its antioxidant and antiapoptosis properties. Journal of Asian Natural Products Research. 2010; 12: 1051-1060.

[86] Liu C, Lin Y, Tang N, Liu H, Huang C, Hsieh C. Effect of oral administration of Pheretima aspergillum (earthworm) in rats with cerebral infarction induced by middle-cerebral artery occlusion. African Journal of Traditional, Complementary, and Alternative Medicines. 2014; 10: 66-82.

[87] Xu XL, Ma CY, Wang XQ, Wang GL, Zhai CM, Yue WC, et al. Comparative study of cholic acid compounds of bezoar on anticerebral infarction and regulating endoplasmic reticulum stress. Drug Evaluation Research. 2017; 040: 11-19.

[88] Li SY, Xie YL, Yu ZH. Notoginseng polysaccharide on rat ischemia-reperfusion injury of Protection Journal of stroke and neurological diseases. Apoplexy and Nervous Diseases. 2015; 32: 996-998.

[89] Yu S, Wang C, Cheng Q, Xu H, Zhang S, Li L, et al. An active component of Achyranthes bidentata polypeptides provides neuroprotection through inhibition of mitochondrial-dependent apoptotic pathway in cultured neurons and in animal models of cerebral ischemia. PLoS ONE. 2014; 9: e109923.

[90] Wang PY, Wang HP, Li GW. Protective effect of pueraria flavonoid on the cerebral ischemic reperfusion injury in rats. China Journal of Chinese Materia Medica. 2006; 31: 577-579. (In Chinese)

[91] Li L, Zhang GQ, Shi XF. Progress in pharmacological research and clinical application of Chenxiang. Asia-Pacific Traditional Medicine. 2019; 15: 199-204.

[92] Nie J, Du L, Lu FY, Shi JS. Inhibitory action of gastrodine on the neuronal apoptosis after focal cerebral ischemia reperfusion. 
ChongQing Medicine. 2012; 1841-1842. (In Chinese)

[93] Meng B, Min DY, G SL. Protective effects of five kinds of traditional Chinese medicine on cerebral ischemia and hypoxia injury. Acta Academiae Medicinae Xuzhou. 2009; 029: 615-617. (In Chinese)

[94] Zhu MF. Effects of Rehmannia glutinosa polysaccharide on peroxidative mitochondrial damage induced by acute cerebral ischemia in mice. Pharmacology and clinic of traditional Chinese Medicine. 2015; 031: 40-43. (In Chinese)

[95] Hu HB, Xia CY, Li GW. Effect of Eugenol inhalation on brain derived neurotrophic factor in SD rats MCAO model. Apoplexy and Nervous Diseases. 2015; 32: 28-32.

[96] Wang X, Wu JZ, Song SL, Wang YS, Liang H, Ji AG. Effects of low molecular weight hirudo peptides on focal cerebral ischemic reperfusion injury in rats. Chinese Journal of Biochemical Pharmaceutics. 2010; 31: 42-44. (In Chinese)

[97] Chen Z, Zhang C, Gao F, Fu Q, Fu C, He Y, et al. A systematic review on the rhizome of Ligusticum chuanxiong Hort. (Chuanxiong) Food and Chemical Toxicology. 2018; 119: 309-325. (In Chinese)

[98] Zhou X, Tang L, Xu Y, Zhou G, Wang Z. Towards a better understanding of medicinal uses of Carthamus tinctorius L. in traditional Chinese medicine: a phytochemical and pharmacological review. Journal of Ethnopharmacology. 2014; 151: 27-43.

[99] Wei G, Chen DF, Lai XP, Liu DH, Deng RD, Zhou JH, et al. Muscone exerts neuroprotection in an experimental model of stroke via inhibition of the fas pathway. Natural Product Communications. 2012; 7: 1934578X1200700.

[100] Zhou L, Zuo Z, Chow MSS. Salvia miltiorrhiza: an overview of its chemistry, pharmacology, pharmacokinetics, and clinical use. Journal of Clinical Pharmacology. 2005; 45: 1345-1359.

[101] Li W, Tang Y, Chen Y, Duan J. Advances in the chemical analysis and biological activities of chuanxiong. Molecules. 2012; 17: 10614-10651.

[102] Yin DD, Wang Y, Yang M, Yin DK, Wang GK, Xu F. Analysis of Chuanxiong Rhizoma substrate on production of ligustrazine in endophytic Bacillus Subtilis by ultra performance liquid chromatography-quadrupole time-of-flight mass spectrometry. Journal of Separation Science. 2019; 42.

[103] Cheng C, Ho T, Lee E-, Su S, Tang N, Hsieh C. Ferulic acid reduces cerebral infarct through its antioxidative and antiinflammatory effects following transient focal cerebral ischemia in rats. The American Journal of Chinese Medicine. 2008; 36: 11051119.

[104] Lin J, Zheng C, Zhang X, Chen J, Liao W, Wan Q. Effects of tetramethylpyrazine on functional recovery and neuronal dendritic plasticity after experimental stroke. Evidence-Based Complementary and Alternative Medicine. 2015; 2015: 394926.

[105] Xu R, Li Y, Huang X. Research progress on pharmacokinetics of Ligustrazine. Journal of Anhui TCM college. 2002; 58-61.

[106] Zhang L, Tian K, Tang Z, Chen X, Bian Z, Wang Y, et al. Phytochemistry and pharmacology of carthamus tinctorius L. The American Journal of Chinese Medicine. 2016; 44: 197-226.

[107] Jia-Xi L, Chun-Xia Z, Ying H, Meng-Han Z, Ya-Nan W, YueXin $\mathrm{Q}$, et al. Application of multiple chemical and biological approaches for quality assessment of Carthamus tinctorius L. (safflower) by determining both the primary and secondary metabolites. Phytomedicine. 2019; 58: 152826.

[108] Sun L, Yang L, Fu Y, Han J, Xu Y, Liang H, et al. Capacity of HSYA to inhibit nitrotyrosine formation induced by focal ischemic brain injury. Nitric Oxide. 2013; 35: 144-151.

[109] Yu L, Chen C, Wang L, Kuang X, Liu K, Zhang H, et al. Neuroprotective effect of kaempferol glycosides against brain injury and neuroinflammation by inhibiting the activation of NF- $x \mathrm{~B}$ and STAT3 in transient focal stroke. PLoS ONE. 2013; 8: e55839.

[110] Hu G, Yu L, Du X, Li Y, Gao X, Chen B. Inhibition of cerebral ischemia/reperfusion injury-induced apoptosis: nicotiflorin and JAK2/STAT3 pathway. Neural Regeneration Research. 2017; 12: 96-102.

[111] Xu H, Liu W, Liu T, Su N, Guo C, Feng X, et al. Synergistic neuroprotective effects of Salvia miltiorrhizasu and hydroxysafflor yellow a on cerebral ischemia-reperfusion injury in rats. Oncotarget. 2017; 8: 115434-115443.

[112] Ji P, Wei Y, Hua Y, Zhang X, Yao W, Ma Q, et al. A novel approach using metabolomics coupled with hematological and biochemical parameters to explain the enriching-blood effect and mechanism of unprocessed Angelica sinensis and its 4 kinds of processed products. Journal of Ethnopharmacology. 2018; 211: 101-116.

[113] Yu G, Zhou Y, Yu J, Hu X, Tang Y, Yan H, et al. Transcriptome and digital gene expression analysis unravels the novel mechanism of early flowering in Angelica sinensis. Scientific Reports. 2019; 9: 10035.

[114] Zhao Y, Sun J, Yu LL, Chen P. Chromatographic and mass spectrometric fingerprinting analyses of Angelica sinensis (Oliv.) Diels-derived dietary supplements. Analytical and Bioanalytical Chemistry. 2013; 405: 4477-4485.

[115] Zhao KJ, Dong TTX, Tu PF, Song ZH, Lo CK, Tsim KWK. Molecular genetic and chemical assessment of radix Angelica (Danggui) in China. Journal of Agricultural and Food Chemistry. 2003; 51: 2576-2583. (In Chinese)

[116] Zhao Z, Guo P, Brand E. The formation of daodi medicinal materials. Journal of Ethnopharmacology. 2012; 140: 476-481.

[117] Giacomelli N, Yang YP, Huber F, Ankli A, Weckerle C. Angelica sinensis (oliv.) diels: influence of value chain on quality criteria and marker compounds ferulic acid and $\mathrm{z}$-ligustilide. Medicines. 2017; 4: 14

[118] Hook IL. Danggui to Angelica sinensis root: Are potential benefits to European women lost in translation A review. Journal of Ethnopharmacology. 2014; 152: 1-13.

[119] Wedge DE, Klun JA, Tabanca N, Demirci B, Ozek T, Baser KHC, et al. Bioactivity guided fractionation and GCMS fingerprinting of angelica sinensis and angelica archangelica root components for antifungal and mosquito Deterrent activity. Journal of Agricultural and Food Chemistry. 2009; 57: 464-470.

[120] Thevis M, Schänzer W, Geyer H, Thieme D, Grosse J, Rautenberg C, et al. Traditional Chinese medicine and sports drug testing: identification of natural steroid administration in doping control urine samples resulting from musk (pod) extracts. British Journal of Sports Medicine. 2012; 47: 109-114.

[121] Yu DQ. Research on artificial musk. Bulletin of Medical Research. 2000; 29: 16-17. (In Chinese)

[122] Wang L, Li J, Xu SF, Feng N, Zhang S, Wang XL. Therapeutic effects of artificial musk on acute ischemic stroke and subarachnoid hemorrhage in rats. Acta Pharmaceutica Sinica. 2019; 54: $1036-$ 1040.

[123] He Y, Wang J, Liu X, Xu Y, He Z. Influences of musk administration on the doping test. Steroids. 2013; 78: 1047-1052.

[124] Zhou Z, Dun L, Wei B, Gan Y, Liao Z, Lin X, et al. Musk ketone induces neural stem cell proliferation and differentiation in cerebral ischemia via activation of the PI3K/Akt signaling pathway. Neuroscience. 2020; 435: 1-9.

[125] Fei Y, Wang S, Yang L, Qiu Y, Li Y, Liu W, et al. Salvia miltiorrhiza Bunge (Salvia miltiorrhiza) extract attenuates permanent cerebral ischemia through inhibiting platelet activation in rats. Journal of Ethnopharmacology. 2017; 207: 57-66.

[126] Fan Y, Luo Q, Wei J, Lin R, Lin L, Li Y, et al. Mechanism of salvianolic acid $B$ neuroprotection against ischemia/reperfusion induced cerebral injury. Brain Research. 2018; 1679: 125-133.

[127] Park JH, Park OK, Cho J, Chen BH, Kim IH, Ahn JH, et al. Antiinflammatory effect of tanshinone $\mathrm{i}$ in neuroprotection against cerebral ischemia-reperfusion injury in the gerbil hippocampus. Neurochemical Research. 2014; 39: 1300-1312.

[128] Yu X, Lin S, Zhou Z, Chen X, Liang J, Duan W, et al. Tanshinone IIB, a primary active constituent from Salvia miltiorrhza, exhibits neuro-protective activity in experimentally stroked rats. Neuroscience Letters. 2007; 417: 261-265.

[129] Li D, Bao X, Sun H, Zhang D. Research progress in the study of protective effect of tanshinone IIA on cerebral ischemic stroke. 
Yao Xue Xue Bao. 2016; 50: 635-639. (In Chinese)

[130] Li QY, Qiu FR. Research Progress on Metabolism of Tanshinones Metabolism together with Metabolites Interactions in vivo and in vitro. Journal of Hunan University of TCM. 2014; 34: 5256. (In Chinese)

[131] Abdoulaye IA, Guo YJ. A Review of recent advances in neuroprotective potential of 3-N-butylphthalide and its derivatives. BioMed Research International. 2016; 2016: 5012341.

[132] Xu J, Wang Y, Li N, Xu L, Yang H, Yang Z. L-3-n-butylphthalide improves cognitive deficits in rats with chronic cerebral ischemia. Neuropharmacology. 2012; 62: 2424-2429.

[133] Li F, Ma Q, Zhao H, Wang R, Tao Z, Fan Z, et al. L-3-nButylphthalide reduces ischemic stroke injury and increases M2 microglial polarization. Metabolic Brain Disease. 2018; 33: 19952003.

[134] Sun Y, Cheng X, Wang H, Mu X, Liang Y, Luo Y, et al. Dl-3n-butylphthalide promotes neuroplasticity and motor recovery in stroke rats. Behavioural Brain Research. 2017; 329: 67-74.

[135] Diao X, Ma Z, Wang H, Zhong D, Zhang Y, Jin J, et al. Simultaneous quantitation of 3-n-butylphthalide (NBP) and its four major metabolites in human plasma by LC-MS/MS using deuterated internal standards. Journal of Pharmaceutical and Biomedical Analysis. 2013; 78-79: 19-26.

[136] Wang S, Wang H, Guo H, Kang L, Gao X, Hu L. Neuroprotection of Scutellarin is mediated by inhibition of microglial inflammatory activation. Neuroscience. 2011; 185: 150-160.

[137] Liu H, Yang X, Tang R, Liu J, Xu H. Effect of scutellarin on nitric oxide production in early stages of neuron damage induced by hydrogen peroxide. Pharmacological Research. 2005; 51: 205-210.

[138] Zhang H, Hu X, Wang L, Xu S, Zeng F. Protective effects of scutellarin against cerebral ischemia in rats: evidence for inhibition of the apoptosis-inducing factor pathway. Planta Medica. 2008; 75: 121-126.

[139] Xiong Z, Liu C, Wang F, Li C, Wang W, Wang J, et al. Protective effects of breviscapine on ischemic vascular dementia in rats. Biological \& Pharmaceutical Bulletin. 2006; 29: 1880-1885.

[140] Yuan Y, Fang M, Wu C, Ling E. Scutellarin as a potential therapeutic agent for microglia-mediated neuroinflammation in cerebral ischemia. Neuromolecular Medicine. 2016; 18: 264-273.

[141] Du X, Chen C, Zhang M, Cai D, Sun J, Yang J, et al. Scutellarin reduces endothelium dysfunction through the PKG-i pathway. Evidence-Based Complementary and Alternative Medicine. 2015; 2015: 430271.

[142] Yuan Y, Rangarajan P, Kan EM, Wu Y, Wu C, Ling E. Scutellarin regulates the Notch pathway and affects the migration and morphological transformation of activated microglia in experimentally induced cerebral ischemia in rats and in activated BV-2 microglia. Journal of Neuroinflammation. 2015; 12: 11.

[143] Wang L, Ma Q. Clinical benefits and pharmacology of scutellarin: a comprehensive review. Pharmacology \& Therapeutics. 2019; 190: 105-127.

[144] Espíndola KMM, Ferreira RG, Narvaez LEM, Silva Rosario ACR, da Silva AHM, Silva AGB, et al. Chemical and pharmacological aspects of caffeic acid and its activity in hepatocarcinoma. Frontiers in Oncology. 2019; 9: 541.

[145] Liang G, Shi B, Luo W, Yang J. The protective effect of caffeic acid on global cerebral ischemia-reperfusion injury in rats. Behavioral and Brain Functions. 2015; 11: 18.

[146] Yang J, Zhou Q, Liu B, He B. Protection of mouse brain from aluminum-induced damage by caffeic acid. CNS Neuroscience \& Therapeutics. 2008; 14: 10-16.

[147] Bat-Erdene B, Orgoi S, Sandag E, Namkhai U, Badarch B, Batsuuri B. Inferior vena cava stenosis-induced sinusoidal obstructive syndrome after living donor liver transplantation. Korean Journal of Hepato-Biliary-Pancreatic Surgery. 2016; 20: 133-136.

[148] Fan F, Yang L, Li R, Zou X, Li N, Meng X, et al. Salidroside as a potential neuroprotective agent for ischemic stroke: a review of sources, pharmacokinetics, mechanism and safety. Biomedicine \& Pharmacotherapy. 2020; 129: 110458.
[149] Guo N, Ding WM, Wang Y, Hu ZW, Wang ZM, Wang Y. An LC-MS/MS method for the determination of salidroside and its metabolite $\langle\mathrm{i}\rangle \mathrm{p}</ \mathrm{i}\rangle$-tyrosol in rat liver tissues. Pharmaceutical Biology. 2014; 52: 637-645.

[150] Xu R, Hu CJ, Wang C, Xiao HT, Tang L, Study on the chemical constituents in antioxidant activity part of Semiaquilegia adoxoides. Chinese Journal of Pharmaceuticals. 2017; 28: 1229-1231. (In Chinese)

[151] Liu X, Wen S, Yan F, Liu K, Liu L, Wang L, et al. Salidroside provides neuroprotection by modulating microglial polarization after cerebral ischemia. Journal of Neuroinflammation. 2018; 15 : 39.

[152] Hu Y, Lv X, Zhang J, Meng X. Comparative study on the protective effects of salidroside and hypoxic preconditioning for attenuating anoxia-induced apoptosis in pheochromocytoma (PC12) cells. Medical Science Monitor. 2016; 22: 4082-4091.

[153] Wang X, Hou Y, Li Q, Li X, Wang W, Ai X, et al. Rhodiola crenulata attenuates apoptosis and mitochondrial energy metabolism disorder in rats with hypobaric hypoxia-induced brain injury by regulating the HIF-1 $\alpha /$ microRNA 210/ISCU1/2(COX10) signaling pathway. Journal of Ethnopharmacology. 2019; 241: 111801.

[154] Cai L, Li Y, Zhang Q, Sun H, Yan X, Hua T, et al. Salidroside protects rat liver against ischemia/reperfusion injury by regulating the GSK-3 $\beta / \mathrm{Nrf2-dependent} \mathrm{antioxidant} \mathrm{response} \mathrm{and} \mathrm{mito-}$ chondrial permeability transition. European Journal of Pharmacology. 2017; 806: 32-42.

[155] Zuo W, Yan F, Zhang B, Hu X, Mei D. Salidroside improves brain ischemic injury by activating $\mathrm{PI} 3 \mathrm{~K} / \mathrm{Akt}$ pathway and reduces complications induced by delayed tPA treatment. European Journal of Pharmacology. 2018; 830: 128-138.

[156] Zou Y. Effects of salidroside-pretreatment on neuroethology of rats after global cerebral ischemia-reperfusion. Journal of Chinese Integrative Medicine. 2009; 7: 130-134. (In Chinese)

[157] Chen X. Study on the protective effect and mechanism of salidroside on neuronal damage[Master's thesis]. Suzhou University: Suzhou. 2009. (In Chinese)

[158] Deheng C, Kailiang Z, Weidong W, Haiming J, Daoliang X, Ningyu C, et al. Salidroside promotes random skin flap survival in rats by enhancing angiogenesis and inhibiting apoptosis. Journal of Reconstructive Microsurgery. 2016; 32: 580-586.

[159] Hu H, Li Z, Zhu X, Lin R, Chen L. Salidroside reduces cell mobility via NF- $x$ B and MAPK signaling in LPS-Induced BV 2 microglial cells. Evidence-Based Complementary and Alternative Medicine. 2014; 2014: 383821.

[160] Wang C, Wang Z, Zhang X, Zhang X, Dong L, Xing Y, et al. Protection by silibinin against experimental ischemic stroke: upregulated pAkt, pmTOR, $\mathrm{HIF}-1 \alpha$ and $\mathrm{Bcl}-2$, down-regulated Bax, NF- $x$ B expression. Neuroscience Letters. 2012; 529: 45-50.

[161] Darbinyan V, Kteyan A, Panossian A, Gabrielian E, Wikman G, Wagner $\mathrm{H}$. Rhodiola rosea in stress induced fatigue-a double blind cross-over study of a standardized extract SHR-5 with a repeated low-dose regimen on the mental performance of healthy physicians during night duty. Phytomedicine. 2000; 7: 365-371.

[162] Zhang Y, Li L, Lin L, Liu J, Zhang Z, Xu D, et al. Pharmacokinetics, tissue distribution, and excretion of salidroside in rats. Planta Medica. 2013; 79: 1429-1433.

[163] Bai J, Zhang Y, Tang C, Hou Y, Ai X, Chen X, et al. Gallic acid: Pharmacological activities and molecular mechanisms involved in inflammation-related diseases. Biomedicine \& Pharmacotherapy. 2021; 133: 110985.

[164] Nouri A, Heibati F, Heidarian E. Gallic acid exerts antiinflammatory, anti-oxidative stress, and nephroprotective effects against paraquat-induced renal injury in male rats. NaunynSchmiedeberg's Archives of Pharmacology. 2021; 394: 1-9.

[165] Lee J, Oh M, SeokJH, Kim S, Lee DB, Bae G, et al. Antiviral effects of black raspberry (rubus coreanus) seed and its gallic acid against influenza virus infection. Viruses. 2016; 8: 157.

[166] Lima KG, Krause GC, Schuster AD, Catarina AV, Basso BS, De Mesquita FC, et al. Gallic acid reduces cell growth by induction 
of apoptosis and reduction of IL-8 in HepG2 cells. Biomedicine \& Pharmacotherapy. 2016; 84: 1282-1290.

[167] Rasooly R, Choi HY, Do P, Morroni G, Brescini L, Cirioni O, et al. whISOBAX TM inhibits bacterial pathogenesis and enhances the effect of antibiotics. Antibiotics. 2020; 9: 264.

[168] Schimites PI, Segat HJ, Teixeira LG, Martins LR, Mangini LT, Baccin PS, et al. Gallic acid prevents ketamine-induced oxidative damages in brain regions and liver of rats. Neuroscience Letters. 2020; 714: 134560.

[169] Kim M, Seong A, Yoo J, Jin C, Lee Y, Kim YJ, et al. Gallic acid, a histone acetyltransferase inhibitor, suppresses $\beta$-amyloid neurotoxicity by inhibiting microglial-mediated neuroinflammation. Molecular Nutrition \& Food Research. 2021; 55: 1798-1808.

[170] Liu Y, Hsu C, Huang H, Chang C, Sun S, Lin AM. Gallic Acid attenuated LPS-induced neuroinflammation: protein aggregation and necroptosis. Molecular Neurobiology. 2020; 57: 96-104.

[171] Reng DD. Neuroprotective effects and its mitochondrial mechanisms of gallic acid on ischemic stroke injury.[Master's thesis] Jiangsu university: Jiangsu. 2017. (In Chinese)

[172] Ahn C, Jung W, Park S, Kim Y, Kim W, Je J. Gallic Acidg-chitosan modulates inflammatory responses in LPS-stimulated RAW264.7 cells via NF- $x B, A P-1$, and MAPK pathways. Inflammation. 2016; 39: 366-374.

[173] Hsu F, Yang L, Chang S, Wang L, Hsu C, Liu P, et al. Biotransformation of gallic acid by Beauveria sulfurescens ATCC 7159. Applied Microbiology and Biotechnology. 2007; 74: 659-666.

[174] Pellati F, Bruni R, Righi D, Grandini A, Tognolini M, Pio Prencipe F, et al. Metabolite profiling of polyphenols in a Terminalia chebula Retzius ayurvedic decoction and evaluation of its chemopreventive activity. Journal of Ethnopharmacology. 2013; 147: 277-285

[175] Yisimayili Z, Abdulla R, Tian Q, Wang Y, Chen M, Sun Z, et al. A comprehensive study of pomegranate flowers polyphenols and metabolites in rat biological samples by high-performance liq- uid chromatography quadrupole time-of-flight mass spectrometry. Journal of Chromatography. 2019; 1604: 460472.

[176] Tan Y, Miao TG, Feng, DY. Evaluation of clinical efficacy of three Chinese patent medicines in convalescent stage of cerebral apoplexy. Journal of Liaoning University of Traditional Chinese Medicine. 2012; 014: 34-35. (In Chinese)

[177] Kapil N, Datta YH, Alakbarova N, Bershad E, Selim M, Liebeskind DS, et al. Antiplatelet and anticoagulant therapies for prevention of ischemic stroke. Clinical and Applied Thrombosis/Hemostasis. 2016; 23: 301-318.

[178] Fulgham JR, Ingall TJ, Stead LG, Cloft HJ, Wijdicks EFM, Flemming KD. Management of acute ischemic stroke. Mayo Clinic Proceedings. 2004; 79: 1459-1469.

[179] Diener HC, Bogousslavsky J, Brass LM, Cimminiello C, Csiba L, Kaste M, et al. Management of atherothrombosis with clopidogel in high-risk patients with recent transient ischemic or ischemic stroke. Cerebrovascular Diseases. 2004; 17: 253-261.

[180] Zhang XW. Three advantages of traditional chinese medicine in the treatment of cerebral apoplexy. Shanghai Journal of Traditional Chinese Medicine. 2006; 40: 1-2. (In Chinese)

[181] Wang JX. Research progress of integrated traditional chinese and western medicine in the treatment of ischemic stroke. Nei Mongu Journal of Traditional Chinese Medicine. 2015; 34: 143-143. (In Chinese)

[182] Wu B, Liu M, Liu H, Li W, Tan S, Zhang S, et al. Meta-Analysis of traditional chinese patent medicine for ischemic stroke. Stroke. 2007; 38: 1973-1979.

[183] Hung CY, Chung VC, Wu X, Ho RS, Tang EC, Wu JC, et al. Overview of systematic reviews with meta-analyses on Chinese herbal medicine in stroke management. Advances in Integrative Medicine. 2019; 6: 126-138.

[184] Li YX, Sun JY, Wu RX, Bai JR, Hou Y, Zeng Y, et al. Mitochondrial MPTP: A novel target of ethnomedicine for stroke treatment by apoptosis inhibition. Frontiers in Pharmacology. 2020; 11: 352. 